\title{
BASES PARA UNA PROPUESTA DE REFORMA EN MATERIA DE DELITOS CONTRA LA SALUD PÚBLICA Y DE RESPONSABILIDAD POR EL PRODUCTO
}

\author{
Bases for a law reform proposal on crimes against public health and \\ related to product liability
}

Fernando Londoño Martínez*

\begin{abstract}
Resumen: El presente texto reproduce, con modificaciones que se detallarán, el informe y propuesta de articulado en materia de delitos contra la salud pública y responsabilidad por el producto, solicitado al autor por la Comisión Redactora del Anteproyecto de Código Penal, Ministerio de Justicia 2013-2014. La propuesta estaba destinada a servir de insumo para la deliberación de aquella Comisión. Aspectos sustantivos de la misma fueron recogidos por la Comisión en su Anteproyecto, los que luego se volcarían en el Proyecto de Ley de Nuevo Código Penal, presentado ante el Congreso Nacional por el Ejecutivo el 10 de marzo de 2014 (Mensaje, Boletín N 9.274-07). Más allá de su eventual utilidad de cara a futuras reformas -existiendo una importante en curso- el presente texto es de interés en cuanto ofrece una rápida mirada al tipo de problemas e insuficiencias que plantea el $\$ 14$ sobre "Crímenes y simples delitos contra la salud pública" del Título VI del Libro Segundo de nuestro vigente Código Penal (arts. 313a318), párrafo por lo demás poco abordado en doctrina. El incierto alcance de la figura de ejercicio ilegal de profesiones del área de la salud humana; la dudosa colocación de hipótesis de auténtica responsabilidad por el producto ( $\mathrm{y}$ de infracción a deberes de retirada y advertencia); el incierto y restringido alcance de los objetos materiales de las figuras de fabricación y expendio; y la problemática regla de calificación por los resultados, son todos problemas que, entre otros, emergen de un examen del $\$ 14$, según podrá apreciarse a partir de la fundamentación de las distintas propuestas de articulado.
\end{abstract}

Palabras clave: Reforma penal - delitos contra la salud pública - responsabilidad penal por el producto - ejercicio ilegítimo de profesiones médicas - sustancias peligrosas envenenamiento y adulteración de sustancias destinadas al consumo humano.

Abstract: This paper reflects -with adjustments that in each case will be highlightedthe contents of the report and regulation-proposal on crimes against public bealth and product liability issued by the author on request of the Chilean Criminal Code Drafting Commission (Chilean Justice Department, 2013-2014). The proposal was intended to serve as an input for the Commission's discussion and drafting process. Substantive aspects of the author's proposal were adopted by the Commission in its preliminary draft, which afterwards would become the New Criminal Code Bill, submitted to Congress by the Executive on March 10, 2014 (Mensaje, Boletin No. 9274-07). Beyond its potential use for future reforms (a relevant one is precisely ongoing) this paper is of interest as it offers a quick look at the kind of problems and shortcomings posed by $\$ 14$ on "Crimes against public health" of Book's Two Title VI of the yet in force Chilean Criminal Code (sections 313a-318), a paragraph briefly discussed among Chilean scholars. The uncertain scope of the false personation of medical staff crime (section 313a); the uncertain criminalization of authentic product liability hypothesis (and infringement of recall and warning duties); the uncertain and limited scope of manufacturing and distribution crimes (on the matter of material objects); and the problematic rule that aggravates criminal liability because of pure results or

Este artículo fue recibido el 19 de mayo de 2016, siendo aprobada su publicación el 29 de junio de 2016. 
consequences (section 317), are all problems and shortcomings which, among others, emerge from an examination of $\$ 14$, as can be appreciated through the author's explanation of the various regulation proposals.

Keywords: Criminal law reform - crimes against public health - product liability false personation of medical staff - dangerous substances - poisoning and adulteration of substances intended for human consumption.

\section{Introducción}

En lo que sigue se reproduce el informe y propuesta de articulado en materia de delitos contra la salud pública y responsabilidad por el producto, solicitado al autor por la Comisión Redactora del Anteproyecto de Código Penal, Ministerio de Justicia 2013-2014 (en adelante "la Comisión"). . Tras su discusión y reelaboración por una subcomisión, la mayoría de los aspectos sustantivos de la propuesta (de Parte Especial) fueron recogidos por la Comisión en su Anteproyecto de Código Penal (en adelante "el Anteproyecto"). ${ }^{2}$ Esas propuestas serían luego incorporadas en el Proyecto de Ley de Nuevo Código Penal (en adelante "el Proyecto"), presentado ante el Congreso Nacional por el Ejecutivo el 10 de marzo de 2014 (Mensaje, Boletín N 9.274-07). El pasaje del Anteproyecto al Proyecto se haría en esta materia prácticamente de modo literal, con solo dos modificaciones importantes ${ }^{3}$ (aunque ninguna de ellas tocante a las propuestas de articulado materia de este informe).

* Abogado. Licenciado en Ciencias Jurídicas y Sociales por la Universidad de Chile (2001). Doctor en Derecho por la Università degli Studi di Ferrara (2008). Profesor Asociado de la Facultad de Derecho de la Universidad Diego Portales. Correo: fernando.londono@udp.cl

${ }^{1}$ Convocada por el Ministerio de Justicia durante el gobierno del ex Presidente Sebastián Piñera Echenique (con el importante impulso de la entonces Ministra de Justicia, Patricia Pérez Goldberg y el entonces Subsecretario de Justicia, Juan Ignacio Piña Rochefort, quien la presidió), fue integrada de manera permanente por los Profesores Juan Domingo Acosta Sánchez, Antonio Bascuñán Rodríguez, Jorge Bofill Genzsch (Coordinador), Juan Pablo Cox Leixelard, Héctor Hernández Basualto, Francisco Maldonado Fuentes y Alex van Weezel de la Cruz. La Comisión solicitó la colaboración ad honorem de más de treinta especialistas nacionales, a quienes en general se encargó la formulación de una propuesta de articulado - por área - que pudiera servir de base para una discusión en su seno. Al suscrito le fue solicitada colaboración para dos distintos capítulos de delitos, uno de cuyos informes se ofrece aquí. El informe se elaboró ajustándose en todo a las directrices de formato y recurso a fuentes internas y comparadas requeridas por la Comisión. Para la publicación en este medio se han realizado modificaciones de forma y estilo, amén de notas para permitir un cotejo con el texto del Proyecto finalmente presentado al Congreso Nacional. Igualmente se incluyeron algunas pocas notas dando cuenta de bibliografía nacional pertinente, no publicada al tiempo de elaboración del informe. En lo demás, la responsabilidad por omisiones e inconsistencias es de exclusiva responsabilidad del suscrito, a quien no queda más que reiterar los agradecimientos a la Comisión por la confianza conferida y la generosidad con la cual fueron en general acogidas sus propuestas de articulado.

${ }^{2}$ El texto del Anteproyecto nos fue gentilmente remitido por vía electrónica a quienes colaboramos externamente con la Comisión. Lamentablemente, hasta donde alcanzo a ver, el Anteproyecto no ha sido divulgado, al menos no oficialmente por los integrantes de la Comisión. Por esa razón es que se ha optado por limitar el cotejo del articulado al solo Proyecto de ley, que en cambio sí es consultable por el público (a través del sitio web del Congreso Nacional).

${ }^{3}$ Hecho un cotejo del párrafo $4^{\circ}$ dedicado a los delitos contra la salud pública, así como a las disposiciones comunes pertinentes del Anteproyecto y del Proyecto, puede advertirse que el 
La publicación de este informe ha permitido reeditarlo con modificaciones de forma y estilo, pero por sobre todo ha permitido ofrecer al lector una comparación ágil entre las propuestas originales del informe y aquellas incorporadas en el Proyecto de Ley. El cotejo se ofrece recurriendo siempre al aparato de notas, para permitir la lectura lineal del informe, conforme a su original. Se incluye además un apéndice con un cuadro comparado. La reedición ha permitido también incorporar referencias bibliográficas nacionales no disponibles al tiempo del informe. Ellas son de interés para seguir la discusión que entre nosotros ha comenzado a darse en torno a algunas de las figuras que ocupan a este trabajo (especialmente en torno a los arts. 313d y 315 del CP). En fin, unas pocas notas se han incorporado para una mejor captación del contexto regulado.

Para cerrar esta introducción no resta más que decir que el presente trabajo, preparado a su tiempo para el uso exclusivo de la Comisión, se ofrece ahora al público especializado, con la esperanza de que pueda servir -si ya, no como propuesta para una reforma sectorial- al menos para una identificación de algunos de los problemas que plantea el $\$ 14$ sobre "Crímenes y simples delitos contra la salud pública”, Título VI, Libro Segundo de nuestro (todavía) vigente Código Penal (en adelante $\mathrm{CP}$ ). Entre esas dificultades se cuenta el incierto alcance de la figura de ejercicio ilegal de profesiones del área de la salud, la dudosa colocación de hipótesis de auténtica responsabilidad por el producto ( $\mathrm{y}$ de infracción a deberes de retirada y advertencia), el restringido (e incierto) alcance de los objetos materiales de las figuras de fabricación y expendio, $\mathrm{y}$, por fin, la problemática regla de calificación por los resultados. De ello, y más, se espera dar cuenta en lo que sigue, a propósito de las fundamentaciones generales y particulares de las propuestas de reforma.

\section{A. Fundamentación general. Premisas generales para una regulación penal del sector}

En este primer apartado (A) se dará cuenta de los aspectos generales que explican y caracterizan la propuesta presentada a la Comisión y que, como se ha anticipado, sirvió en definitiva para la elaboración del Proyecto. En un

respectivo articulado de la Comisión fue incorporado prácticamente sin modificaciones en el Proyecto (enmiendas menores pueden apreciarse en los arts. 539 y 554 del Proyecto $=542$ y 555 del Anteproyecto, respectivamente), con dos importantes salvedades. En primer lugar, el Proyecto incorporó dos nuevas figuras autónomas en el párrafo $4^{\circ}$, como artículos 541 y 542, dedicadas a la tipificación de la extracción ilegal de órganos de un cadáver y el tráfico de órganos, respectivamente. En fin, mientras el Anteproyecto de la Comisión (art. 182 N¹4) incluía todo el párrafo de delitos contra la salud pública entre aquellos que podían gatillar la responsabilidad penal de las personas jurídicas - con la sola excepción de cuatro figuras, posiblemente aquellas más directamente reconducibles a la infracción de deberes individuales: prácticas eugenésicas y de asistencia a la procreación, ejercicio ilegal y omisión de denuncia de enfermedad contagiosa- el Proyecto (art. $181 \mathrm{~N}^{\circ}$ ) ) limitó fuertemente aquello, reduciendo el ámbito de responsabilidad de las personas jurídicas a las mismas dos figuras nuevas incorporadas en el Proyecto (arts. 541 y 542). Esta misma restricción se dio en otros ámbitos de delitos, pero ello no es competencia de este trabajo. 
segundo apartado (B) se expondrán las fundamentaciones particulares, para cada una de las soluciones de articulado propuestas.

\section{A.I. Rúbrica o campo de cobertura}

En conformidad al encargo de la Comisión, la propuesta aborda los delitos relativos a la salud pública, con exclusión del tráfico ilícito de estupefacientes (también de acuerdo a lo solicitado).

La rúbrica delitos relativos contra la salud pública posee un significativo espacio de ambigüedad. En efecto, no es unívoco el campo de figuras asociables al concepto de salud pública, desde ya atendiendo a la situación del derecho comparado, en el que bien podría plantearse la reconducción a dicha rúbrica de ciertas figuras dispersas en el campo de los delitos de peligro común.

Ahora bien, la idea de delitos contra la salud pública aquí asumida es de cuño principalmente hispano-italiana, pudiendo identificarse en dichas tradiciones un núcleo ineludible de delitos cubiertos por la rúbrica; a saber, aquellos relativos a los peligros generados por la circulación de productos de consumo o aplicación humana, especialmente alimentos, medicinales y otros géneros dotados de intrínseca toxicidad o potencial lesivo (incluyéndose en la propuesta aquellos destinados a cautelar riesgos propios de determinadas actividades). Con esto, la propuesta se abre a regular penalmente lo que modernamente se conoce como responsabilidad por el producto.

Otras figuras se considerarán igualmente bajo la rúbrica, como las relativas a mataderos clandestinos y omisión de notificación para casos de determinados brotes infecciosos.

Por otra parte, se hace presente que no se han considerado aqui ${ }^{4}$ (1) las disposiciones relativas a inhumaciones y exhumaciones de cadáveres humanos (pues la esfera de interés excede allí, con mucho, la mera dimensión de la salud pública, no obstante ser materia de un cuerpo como el Código Sanitario $)^{5}$; (2) las figuras

\footnotetext{
${ }^{4}$ Además de las tres categorías cuya exclusión a continuación se anuncian, la propuesta tampoco incorporaba figuras penales relativas a prácticas eugenésicas o manipulativas del genoma humano, asistencia indebida a la procreación o tráfico de órganos, por no entenderse estrictamente acotadas a esta rúbrica. El Proyecto contemplaría en definitiva figuras para aquellos sub-sectores, ubicándolas en el mismo párrafo 4 del Título XIV, dedicado a los delitos contra la salud pública: cfr. arts. 539 a 452 del Proyecto.

${ }^{5}$ Considérese que el CP vigente trata estos delitos en un párrafo sucesivo al dedicado a los delitos contra la salud pública; esto es, el $\$ 15$ del Título VI del Libro Segundo, de la infracción de las leyes o reglamentos sobre inbumaciones y exhumaciones (arts. 320, 321 y 322 del CP). Si acaso la tipificación de las inhumaciones (art. 320 CP) y exhumaciones ilegales (art. 322 CP) se deja explicar en atención a meras razones de salud pública es algo que puede discutirse (hay también razones de administración de justicia en ello, incluso sin incomodar nociones metafísicas o culturales en torno al ser humano y su cuerpo), pero parece fuera de discusión que el ultraje de sepulcros y cadáveres (art. $321 \mathrm{CP}$ ) no se castiga en atención a la salud pública. Atendiendo en parte a estas consideraciones, la Comisión optó por dividir la rúbrica del aludido $\$ 15$ del vigente $\mathrm{CP}$, llevando lo relativo a ultrajes de sepulcros y cadáveres a un párrafo independiente (vinculado a los atentados contra el orden público: arts. 473 y 474 del Proyecto) y dejando bajo
} 
de peligro asociadas a material radioactivo ionizante y energía nuclear (en la medida que ellas empalman -más adecuadamente- con el tratamiento de otras figuras de peligro común); y (3) las figuras relativas a las epizootias y salud animal o vegetal en general (por considerarse que su tratamiento se adapta mejor a la problemática de los delitos ecológicos). En todo caso, es posible que algunas de las figuras propuestas puedan igualmente captar determinadas hipótesis comprendidas en estas últimas dos rúbricas, ya bajo el supuesto de alimentos (en el caso de carnes y vegetales destinados a consumo humano), ya bajo el supuesto de sustancias peligrosas (en el caso de materiales radioactivos).

Por fin, por lo que toca a aspectos directamente vinculados con la Parte General, la propuesta incursiona en 1) una regla de imputación de responsabilidad (de asignación de responsabilidad a título de autoría o de mera intervención) pensada para contextos organizados-empresariales, y 2) en una regla de desistimiento o arrepentimiento eficaz. No incursiona en cambio en aspectos que atañen al iter criminis $^{6}$ (más allá de ofrecer una sugerencia muy general) o a la responsabilidad penal de las personas jurídicas, ${ }^{7}$ por entender que aquellas materias deben quedar entregadas a la solución general que buenamente prevea la Comisión.

\section{A.II. Legislación Nacional}

En el caso del CP chileno, la rúbrica coincide con el \$14, Título VI, del Libro Segundo (arts. $313 \mathrm{a}-318$ ), original de 1874 , modificado luego por la ley $\mathrm{N}^{\mathrm{o}}$ 17.155 de $1969 .^{\circ}$ En dicho párrafo se contemplan las tradicionales figuras

la rúbrica de delitos contra la salud pública las figuras de inhumación y exhumación ilegal (art. 554 del Proyecto).

${ }^{6}$ En definitiva el Proyecto excluiría la punibilidad de la tentativa para la generalidad de estos delitos. En efecto, habida cuenta de la regla de excepcional punibilidad de la tentativa de simples delitos (art. 31 del Proyecto en relación con el art. 43) y las disposiciones comunes del párrafo en cuestión (art. 570 Proyecto), solo se previó la punibilidad de la tentativa para dos de los delitos más graves de entre los propuestos (envenenamiento de sustancias y diseminación de gérmenes patógenos: arts. 549 y 550 del Proyecto), ambos sancionados con pena de crimen (y por tanto punibles en tentativa por regla general). El suscrito concuerda en general con aquella solución, como se desprende del tenor de un pasaje del propio informe. En fin, es importante destacar que respecto de aquellos dos delitos (envenenamiento de y diseminación de gérmenes), el Proyecto hace también punible la conspiración (art. 571).

${ }^{7} \mathrm{Al}$ respecto, cfr. supra nota 3.

${ }^{8} \mathrm{El}$ actual $\$ 14$ del Título VI fue introducido por la ley $\mathrm{N}^{\circ} 17.155$ (DO. 11.06.69) en reemplazo del párrafo de igual rúbrica, originario de 1874. Contenía dicho párrafo - que en lo fundamental se basó en el CP español de 1848 - una serie de delitos de peligro común para la salud individual, enmarcados en el ámbito de la denominada salud pública; a saber: la elaboración y tráfico ilegal o irregular de sustancias o productos nocivos a la salud (arts. 313 y 314); el delito especial de despacho de medicamentos deteriorados, con peligro para la salud (art. 315); la alteración, con mezclas nocivas a la salud, de bebidas y comestibles destinados al consumo público o de aguas destinadas a la bebida, así como la sustracción, para efectos comerciales, de objetos destinados a ser inutilizados o desinfeccionados (arts. 316 y 317); y la infracción de reglas higiénicas o de salubridad acordadas por la autoridad en tiempo de epidemia o contagio (art. 318). El legislador de 1969, atribuyendo "insuficiencia" al párrafo originario, y con miras a lograr una regulación penal más acorde al moderno desarrollo químico-industrial y comercial, propició su reemplazo por el actual (Cfr. Mensaje de S.E. el Pdte. de la República, en Boletín del Congreso Nacional Dip. Extr, 1966-67, II, Ses. 18 a 23.11.1966, pag. 1683; en el mismo sentido, ETCHEBERRY (1997), t. IV, p. 282. De otra opinión es COUSIÑO (1975), t. I, p. 879, quien, posiblemente condicionado por el fragor 
relativas a la circulación de productos peligrosos (arts. 313-d, 314, 315, amén de 317 como disposición común), incluyéndose además dos figuras relativas al ejercicio de la medicina y profesiones afines (arts. 313-a y 313-b), junto con otras dos vinculadas a la diseminación de gérmenes patógenos e infracciones en contextos de epidemia, catástrofe o contagio (arts. 316 y 318).

Siempre en el CP chileno, a lo menos cinco figuras de faltas resultan atingentes a la rúbrica: despacho de medicamento sin receta y ejercicio ilegal de medicina y otras afines (art. $494 \mathrm{~N}^{\circ} \mathrm{s} 7$ y 8) y disposición no reglamentaria de animales muertos, objetos insalubres y desperdicios (art. $496 \mathrm{~N}^{\circ}$ s 19, 20 y 22). En fin, otras figuras penales contenidas en leyes especiales pueden considerarse en este mismo contexto: mataderos clandestinos (arts. 3 y 4 de la ley $\mathrm{N}^{\mathrm{o}}$ 11.564), venta de productos alimenticios adulterados (art. 170 de la ley $\mathrm{N}^{\circ}$ 16.464) y expendio de alcoholes nocivos (art. 42 de la ley $\mathrm{N}^{\text {o }}$ 18.455). Los textos de este último grupo se incluyen en notas al pie en el artículo $\mathrm{M}$ de esta propuesta (artículo derogatorio).

Por lo que se refiere a las normas primarias o complementarias de los tipos en blanco -de rango legal o reglamentario- su mención aquí chocaría con el esfuerzo sintético. En la fundamentación particular del articulado se mencionarán las principales, pero puede anticiparse que, en lo grueso, se trata del Código Sanitario (en adelante CSanitario), especialmente sus Libros III, IV, $\mathrm{V}$ y VI, y de su poco menos que abrumadora normativa complementaria, de rango reglamentario (cfr. edición disponible en el sitio web del Ministerio de Salud, incluyendo anotaciones pertinentes actualizadas).

\section{A.III. Derecho Comparado y propuestas consultadas}

Los código penales y proyectos de obligada referencia para la Comisión han sido por cierto consultados para elaborar esta propuesta; a saber: CP español de 1995 (especialmente arts. 359-367, 402-403); StGB alemán (especialmente $\iint 132 \mathrm{a}, 145 \mathrm{c}, 314$ y 314a); y el Anteproyecto Comisión Foro Penal (especialmente arts. 192-198; 228-233; 248-250).

de su contienda "contra" los artículos 313 c y 317 - en los que reconoce casos de delitos calificados por el resultado -, no ve en la ley más que un "fárrago de substituciones de Párrafos y Artículos”). No consta en la historia fidedigna de la ley $\mathrm{N}^{\circ} 17.155$ que se haya seguido o tenido a la vista algún modelo específico de derecho comparado. Puede en todo caso advertirse una nota de familiaridad con el texto del CP español de 1944, al menos en la norma del inciso $1^{\circ}$ del art. 317, que asume la agravación por el resultado contemplada por el muy criticado art. 348 del CP español. Grosso modo, la nueva regulación significó la enmienda, complemento o ampliación de las mencionadas figuras (principalmente en el ámbito de los delitos de adulteración de fármacos y alimentos), así como la incorporación de otras nuevas en este contexto: el curanderismo o charlatanismo (art. 313-b), la diseminación de gérmenes patógenos (actual art. 316) y la primera regulación penal especial sobre tráfico ilícito de sustancias estupefacientes (originales arts. 319-a y ss., posteriormente derogados por la ley No 17.934 de 1973). En cuanto al ejercicio ilegal de profesiones de la salud, se incorporó su sanción a título de simple delito (art 313-a), en circunstancias que desde el CP de 1874 se sancionaba como falta por el $\mathrm{N}^{\circ} 8$ del art. 494. Sin perjuicio de la mencionada derogación de las figuras dedicadas al tráfico ilícito de estupefacientes, de las modificaciones en materia de multas por el D.L. No2.059 de 1977 (que elevó los montos) y de la ley No 19.450 de 1996 (que reemplazó los sueldos vitales por UTM), el párrafo en comento no ha sido objeto de reformas ulteriores. 
Además, se ha tenido a la vista el CP italiano (especialmente arts. 348 y 438-448), la italiana legge 283/1962 (produrione e vendita di sostanze alimentari e bevande, arts. 5 y 6), la alemana $A M G$ (Gesetz über den Verkehr mit Ar₹neimitteln, $\mathbb{S}$ 95 y 96 ) y la legislación federal de los Estados Unidos: Consumer Product Safety Act (15 USC SS 2068 y 2070) y Federal Food, Drug and Cosmetic Act (21 USC SS 331 у 333).

\section{A.IV. Caracterización general de la propuesta}

Se ha seguido de cerca la legislación nacional vigente, así como el Proyecto Comisión Foro Penal, apartándose, complementándose o innovándose allí donde ha parecido adecuado. Para tipos o pasajes puntuales se han seguido o adaptado formulaciones del derecho comparado arriba citado, que se procurará indicar en cada caso, en el marco de la fundamentación particular o bien en notas al pie en el propio articulado. No se ha pretendido innovar demasiado (salvo en tres o cuatro materias), tratándose este de un sector casi no sometido a prueba por nuestra praxis.

La propuesta asume una moderada "expansión" del ámbito penalmente regulado. Si bien las figuras nuevas son escasas, el cuadro general es el de una relativa ampliación de la cobertura penal. Con todo, se ha procurado establecer parámetros de entidad y gravedad (a veces con formulaciones complementarias), para evitar una sobre-criminalización "bagatelizadora" del sector. De este modo, las figuras penales propuestas deberían estar en condiciones de hacerse cargo solo de aquellas expresiones de peligro particularmente significativas, ya por la amplia apertura de su alcance (casos de peligro común), ya por su potencial de lesividad (limitaciones en función del tipo de resultados posibles). El riesgo de una judicialización extrema debe aquí temerse tanto como el riesgo de una desprotección "neo-liberal".

El semblante general del articulado debería dar cuenta de un aggiornamento del derecho penal del sector (en buena medida aún decimonónico, no obstante la reforma de 1969), ${ }^{9}$ de modo que pueda moldearse mejor a las actuales realidades productivas, que suponen la intervención de múltiples agentes, en planos y funciones diferenciadas. ${ }^{10} \mathrm{En}$ esa "multiplicidad" ocupa también un espacio la administración pública, de modo que se han contemplado figuras pertinentes para asegurar la responsabilidad de funcionario públicos que puedan favorecer la actuación delictiva de particulares. ${ }^{11}$

\footnotetext{
${ }^{9}$ La estructura y los verbos rectores de una figura como el art. 315 del CP dan cuenta de ello. Cfr., Cousiño (1975), p. 879 quien no ve en la reforma de 1969 más que un "fárrago de substituciones de Párrafos y Articulados", si bien en el marco de su lucha personal contra las figuras de calificación por el resultado.

${ }^{10}$ Algo que en todo caso no escapaba a los autores o legisladores del s. XIX: cfr., por ejemplo, el CP austríaco de 1803 y las figuras destinadas a sancionar a los boticarios y a sus dependientes, arts. 100 ss. Así, PACHECO (1870), t. II, pp. 360 y ss.

${ }^{11} \mathrm{Si}$ bien en este punto la Parte General -con sus reglas en materia de intervención delictiva- o aún el capítulo de delitos funcionarios, deberían ser tanto o más adecuados para asegurar este tipo de responsabilidad.
} 
En fin, se ha tenido a la vista el derecho administrativo de sector, procurando un anclaje en clave de accesoriedad. Se ha resistido la tentación de ofrecer figuras penales caídas de un cielo teórico, siguiendo -en las voces empleadas y en los marcos de referencia- formulaciones que encuentran eco en la normativa reglamentaria.

\section{A.V. Estructura y figuras en general}

Se han conservado estructuras propias de delitos de peligro, privilegiándose en general fórmulas caracterizables como de peligro abstracto-concreto o de idoneidad (si bien algunas de ellas podrían interpretarse como de peligro concreto). La formulación de tipos en blanco, o bien el recurso a voces amplias, parece casi inevitable en este ámbito, sobre todo si se trata de legislar desde el Código Penal, y no desde los cuerpos de sector. Allí donde ha sido posible, se ha procurado dar con formulaciones lineales y sintéticas, afrontando sin embargo un riesgo de ambigüedad y las consecuentes repercusiones en el plano de la legalidad.

En cuanto a la tipicidad subjetiva, no hay alusiones explícitas al dolo (salvo por lo que se refiere a una regla de calificación en caso de resultados), incluyéndose una disposición que amplifica la tipicidad hacia la imprudencia (al menos para un grupo de figuras). En lo demás, se asume un modelo compatible con el principio de culpabilidad, atendiendo a las diferencias entre principales y subordinados, pero de ningún modo sugiriendo que la sola "posición principal" de un agente en el seno de una persona jurídica sea suficiente para hacerlo responsable penalmente. Se propone en este contexto una regla de imputación para actuaciones individuales en el seno de dichas realidades colectivas (art. F). Una regla semejante es por cierto prescindible en la medida que se contemplen disposiciones comunes o de Parte General.

Nada se propone en materia de iter criminis, no conociéndose por el suscrito las decisiones marco que adoptará la Comisión al respecto. Se anticipa en todo caso que, en el evento de adelantarse en demasía su punibilidad, varias de las figuras plantearían escenarios de incertidumbre no deseable (piénsese sobre todo en las conductas de elaboración de productos). ${ }^{12}$ Considérese en este contexto el destino casi inexorable de estas figuras; a saber, solo se les procura aplicar allí donde, lamentablemente, ya hay muertes y lesionados (y cuando se aplican, muchas veces se hace en circunstancias en las que no se ha podido acreditar una causalidad, de manera que su aplicación termina por resultar parcialmente insatisfactoria). ${ }^{13}$

En cuanto a las penas, cabe decir otro tanto: no se identifican penas concretas ni tramos de penas de presidio, no conociéndose el sistema ni rango de penas a adoptar por la Comisión. Con un sistema de asteriscos $\left(^{*}\right)$, representando cada asterisco una unidad hipotética de medida, se intenta

\footnotetext{
12 Véase supra la nota 6.

${ }^{13}$ Cfr. en nuestro medio el conocido "caso leche Adn" o "del alimento enteral": con sentencia por el T.O.P. de San Bernardo de 24 de agosto de 2012, RIT 38 - 2011, y con fallo de la Corte Suprema en Recurso de Nulidad de 27 de diciembre de 2012, Rol N 6831-12. A respecto, cfr. CONTRERAS (2015), pp. 271 y ss.
} 
advertir sobre el nivel de gravedad que se pretende para cada figura, en escala relativa, interna a la rúbrica. En cuanto al tipo de penas, se sugieren las habituales para este sector: privaciones de libertad, inhabilitaciones (profesionales o para contratar) y eventualmente multas. ${ }^{14}$ En cuanto a las sanciones que puedan afectar a las personas jurídicas, entidades o establecimientos (clausuras, etc.), se espera a la adopción de una regla general de la Comisión en lo pertinente (más allá de la vía administrativa). De cualquier modo, se hace ver que una regla como la propuesta en el art. 229 del Anteproyecto Comisión Foro Penal podría ser de interés aquí.

Las figuras propuestas pueden agruparse del siguiente modo:

Apartado 1. Una figura de ejercicio ilegal de profesiones del área salud, en línea con el actual 313 a CP = art. A.

Apartado 2. Un grupo de figuras en torno a la circulación, con peligro común, de sustancias o elementos destinados a consumo humano, entre las que cabe mencionar:

2.1 Una figura de conducta activa, relativa a alimentos, cosméticos, medicinales y otros productos de uso terapéutico, reconducible a la problemática de la responsabilidad por el producto (por tanto solo parcialmente equivalente a nuestros actuales arts. $313 \mathrm{~d}$ y $315 \mathrm{CP})^{15}=$ art. B

2.2 Una figura de conducta omisiva, relativa a dichos elementos (sin equivalencia en la legislación vigente) $=$ art. $\mathrm{C}$

2.3 Una figura de intrusismo y otras similares, relativas a la puesta en circulación de medicinales y cosméticos de manera no autorizada o bien

\footnotetext{
${ }^{14}$ En general este tipo de sanciones se incluyen en el Proyecto, considerándose además la posibilidad de inhabilitación perpetua para el ejercicio de la profesión, conforme a la disposición común de su art. 572.

${ }^{15}$ El tenor de la propuesta es más cercano a la estructura típica del art. 313-d CP que al art. 315 CP. En efecto, nuestro actual art. 315 respondería - con sus verbos rectores envenenar, infectar y adulterar - a una tipificación de formas de sabotaje (exógenas o realizadas "desde afuera" del proceso productivo y distributivo de las sustancias), a diferencia del tenor del art. 313-d CP, en principio compatible con un modelo de responsabilidad penal por el producto (lo que se advierte a partir de los verbos rectores fabricar y expender, en contraste a aquellos del art. 315). Mientras en el art. 313-d es el producto mismo el que explica la punibilidad (en cuanto nocivo), en el art. 315 es la conducta del agente (que envenena, infecta o adultera "desde afuera") la que aparece en primer plano, explicando la punibilidad (y explicando, además, que haya sido seleccionado como figura base del delito terrorista: cfr. art. $2^{\circ}$, num. $1^{\circ}$ de la ley ${ }^{\circ} 18.314$; aunque también lo es el art. 313-d, debe reconocerse). Este aspecto fue discutido especialmente por las defensas en el "caso leche Adn" o "alimento enteral", con razón a mi modo de ver, y rechazado por el T.O.P. de San Bernardo, a mi parecer con una lectura discutible del art. 315, entendiendo la adulteración en términos equiparables a la falsificación de las propiedades aprobadas en abstracto por la regulación de sector, bajo un presupuesto de creación ex novo del objeto material de la conducta (una noción, de hecho, equivalente a la contraffazione italiana para este tipo de delitos: arts. 440 ss. CP italiano): cfr. T.O.P. de San Bernardo, de 24 de agosto de 2012, RIT 38 - 2011. Crítico de la sentencia en este punto, precisamente por este tipo de consideraciones, cfr. el todavía lamentablemente inédito, VIGANÒ (2013). Una opinión distinta se desprendería de CONTRERAS (2015), pp. 271-271 (notas 19 y 20), entendiendo subsumible el caso en cuestión bajo la forma imprudente del art. 315 CP.
} 
incurriendo en conductas de falsedad (sin equivalencia inmediata en la legislación vigente) $=$ art. $\mathrm{D}$

2.4 Una figura amplia - eventualmente residual - relativa a la circulación de otras sustancias peligrosas para la salud (equivalente a nuestro actual $314 \mathrm{CP}$, pero cuyo alcance se propone extender de modo relevante) $=$ art. $\mathrm{E}$

2.5 Una figura de sabotaje vía envenenamiento de sustancias y diseminación de gérmenes patógenos, no enmarcada por tanto en procesos productivos $^{16}$ (parcialmente equivalente a nuestros actuales 315 y $316 \mathrm{CP}$, y en línea con el 314 StGB alemán y 438-439 CP italiano) = art. G

Siempre en apartado 2. Disposiciones parcialmente comunes al grupo de figuras anteriores; a saber:

2.6 Regla de atribución en contextos de acciones ejecutadas en el seno de entidades o personas jurídicas, incluyéndose una regla de atribución para funcionarios públicos $=$ art. $\mathrm{F}$

2.7 Regla de calificación en caso de resultados de muerte o lesión (anticipándose desde ya que se ofrece con importantes dudas y casi solo por lealtad para con el enfrentamiento del problema; se dirá más en la fundamentación particular) $=$ art. $\mathrm{H}$

2.8 Norma de desistimiento o arrepentimiento eficaz (en línea con el (314a StGB) $=$ art. I

2.9 Regla de imputación a título de imprudencia $=$ art. J

Apartado 3. Otras figuras de delitos contra la salud pública:

3.1 Figura de omisión de notificación de posible enfermedad o causa infecciosa cuya inmediata notificación a las autoridades es requerida por ley o reglamento $=$ art $\mathrm{K}$

3.2 Figura relativa a mataderos clandestinos $=$ art. $\mathrm{L}$

\section{B. Fundamentación Particular}

Por razones de espacio, más que una fundamentación propiamente tal, se buscará aquí poner en evidencia -esquemáticamente y casi a modo de apuntesalgunas de las decisiones centrales que cada figura supone. Igualmente, y hasta donde le ha sido posible advertir al suscrito, se intentará destacar el tipo de consecuencias que se pueden desprender de dichas decisiones.

${ }^{16}$ Véase la nota precedente. 
En notas a pie de página se han incorporado -para esta edición- las respectivas referencias atingentes al Proyecto de Código Penal presentado por el Ejecutivo usando como base el Anteproyecto de la Comisión.

En fin, una nota es obligada por lo que atañe a la simbología utilizada en el articulado. En el propio cuerpo del articulado se incluyen formulaciones alternativas o se resaltan pasajes opcionales-complementarios (poniendo así en evidencia las cavilaciones del proponente). Para ello se optó por el uso de [corchetes] o del signo "/", en su caso. Redacciones alternativas pueden también figurar en nota al pie, para completar el cuadro de complicaciones para la Comisión (y todo ello -paradójicamente- pese a que el suscrito ha procurado desarrollar el articulado bajo la arquitectónica consigna less is more). En fin, en cuanto a las penas, se usan asteriscos $\left(^{*}\right)$, para -como ya se ha anticipado- destacar las diferencias de quantum esperables en cada figura (en escala relativa, interna a la rúbrica materia del informe).

\section{B.I. Ejercicio ilegal de profesiones médicas: artículo A de la propuesta (cfr. art. 538 del Proyecto; art. 313-a CP)}

Art. A. Con pena de [*] será sancionado el que, sin contar con la competente habilitación, [ostentare la calidad o] ejerciere actividades propias de [profesiones relacionadas con la conservación y restablecimiento de la salud humana y que requieran licenciatura universitaria] / [la medicina alopática, enfermería, fonoaudiología, kinesiología, obstetricia, nutricionismo, tecnología médica, terapia ocupacional, odontología, química y farmacia, bioquímica $\{\mathrm{y}$ psicología\}].

Con [igual] pena será sancionado el que, validando indebidamente una calidad, decidiendo una contratación, prestando su nombre o de cualquier otra forma relevante, hiciere posible el ejercicio a que se refiere el inciso anterior.

No se entenderá que ejercen actividades propias de las profesiones a que se refiere el inciso primero, ${ }^{17}$ quienes desarrollen actividades circunscritas a las profesiones auxiliares de la salud o bien a la denominada medicina alternativa complementaria \{naturopatía, quiromasaje, acupuntura, terapia floral, homeopatía u otras afines\}, en la medida que se sujeten a las autorizaciones legales o administrativas pertinentes. ${ }^{18}$ Tampoco se entenderá que ejercen actividades propias de las profesiones a que se refiere el inciso primero, quienes practiquen la medicina tradicional de comunidades indígenas, o lleven a cabo otras prácticas afines de inveterada raigambre en el territorio]. ${ }^{19}$

\footnotetext{
${ }^{17}$ Se propone como alternativa una cláusula aclaratoria de exclusión de tipicidad, para el caso que no se considere suficiente una genérica justificante de ejercicio legítimo de derecho u oficio, que posiblemente la Comisión considerará.

${ }^{18}$ Cfr. Decreto No 42 de 2005, Ministerio de Salud, "Reglamento para el ejercicio de las prácticas médicas alternativas como profesiones auxiliares de la salud y de los recintos en que estas se realizan".

${ }^{19}$ Cfr. art. $2^{\circ}$ del Decreto $N^{\circ} 42$ de 2005, Ministerio de Salud, el que excluye de su regulación este tipo de prácticas: "La medicina popular tradicional chilena, entendida como las actividades
} 


\section{Explicación}

La propuesta reconoce aquí un injusto autónomo en la esfera de la salud pública. Se prefiere esta opción, siguiendo en esto al CP vigente (solución excepcional en el marco del derecho comparado consultado). Es también de recibo una alternativa que prevea una mera agravación en el marco de un tipo común de intrusismo (tipo que posiblemente la Comisión considerará para otro Título de delitos). ${ }^{20}$

En seguida, se trata de decidir el rango de profesiones del área salud que quedarán cubiertas (ámbito de cobertura de la figura) ${ }^{21}$. En particular, se trata de decidir:

i. $\quad \mathrm{Si}$ acaso se acotará la cobertura a las tres profesiones centrales o tradicionales en lo pertinente: médico-cirujano, odontólogo y químicofarmacéutico (es la opción de la falta del 494 N. 8, ya en "desuso" y son las tres a que se alude expresamente en el art. 112 CSanitario). La propuesta no sigue esta opción.

ii. Si en cambio se comprenderán todas las profesiones del ámbito que hoy implican título de licenciatura, pero descartando las profesiones auxiliares (algo que la propuesta de la Comisión Foro Penal no aclara del todo y que esta propuesta busca despejar). ${ }^{22}$

En ese marco, toca decidir si se incluirá o no a la psicología (lo que parece no hacer el 313-a, al referirse al "cuerpo humano"). La propuesta se abre a incluirla, considerando su tratamiento por el CSanitario). ${ }^{23}$

Más importante quizás, decidir que no se tutelarán penalmente las especialidades médicas (opción que sigue la propuesta; cfr. discusión en España a propósito del 403 CP 1995). En la discusión en vivo podrán aportarse mayores antecedentes al respecto, pero básicamente la razón obedece al todavía insuficiente desarrollo en Chile de una parte importante de las

y procedimientos de recuperar y mantener la salud, de origen sociocultural autóctono en el país, ejercida por sanadores formados tradicionalmente en sus propias comunidades de pertenencia y que gozan del respeto de estas, quedará al margen de la aplicación de este Reglamento [dedicado a la regulación del ejercicio de las prácticas médicas alternativas como profesiones auxiliares de la salud]".

${ }^{20}$ En definitiva el Proyecto haría suya la idea de reconocer un injusto autónomo para el ejercicio ilegal de profesiones médicas, proponiendo su tipificación a través del art. 538. La figura común de ejercicio ilegal de profesiones encontró su espacio en otro contexto, en el Título de delitos contra la fe pública (art. 410 del Proyecto).

${ }^{21}$ Para un meticuloso esfuerzo en orden a precisar la cobertura del actual art. 313-a CP, con su cláusula analógica, cfr. MiLOS (2012), pp. 197-239.

22 El Proyecto se inclinaría por una opción amplia también, aludiendo a "profesiones relacionadas con la conservación y restablecimiento de la salud humana", con el límite que supone que se trate de aquellas que requieren "licenciatura universitaria": cfr. art. 539 del Proyecto.

${ }^{23}$ Creemos que esta misma decisión puede desprenderse del Proyecto, en cuanto se refiere a la "salud humana" en términos amplios (en lugar de la fórmula "cuerpo humano", en principio más restrictiva). 
especialidades médicas (y principalmente a su escasa cobertura en buena parte del territorio nacional).

En cuanto a la modalidad de cobertura, la propuesta plantea dos alternativas de formulación: una cláusula general (siguiendo las expresiones utilizadas por el CSanitario) y una fórmula de enunciación detallada y taxativa. En esta segunda fórmula se incluyen las ocho carreras asociadas a las facultades de medicina, además de las otras afines y que implican licenciatura (odontología, psicología, química y farmacia, bioquímica). ${ }^{24}$

En cuanto al concepto de ejercicio (ilegal), la propuesta opta por sancionar solo el ejercicio efectivo; se evidencia como opción en corchetes la inclusión de la mera ostentación (una dimensión que no se vincula tanto con la salud pública como con la tutela de la confianza pública y la vigencia de las profesiones) ${ }^{25} \mathrm{En}$ lo demás, el punto se vincula a una discusión sobre iter criminis. ${ }^{26}$

En cuanto al presupuesto de ilegitimidad del ejercicio, se utiliza una fórmula amplia cual "sin la competente habilitación". En este contexto tocará discutir si dar o no cobertura típica al ejercicio bajo suspensión o inhabilitación transitoria como injusto en este contexto, diferenciado por tanto del propio del quebrantamiento. La fórmula propuesta es todavía ambigua en este punto (esta situación está hoy dudosamente cubierta por el 313-a CP; con cobertura en esta línea, el art. 36 DFL No1 de 1970 sobre intrusismo kinesiológico; en derecho comparado, cfr. el 145c StGB). ${ }^{27}$

Por otra parte, se ha optado por suprimir la inexplicable exigencia de habitualidad del ejercicio de actividades propias de la profesión (cfr. 313-a CP).

En cuanto a la situación concursal y el iter criminis, se entrega por completo a las reglas de Parte General que el Proyecto contemple en definitiva. Asimismo, no se propone extender la regla de calificación por los resultados para esta figura $^{28}$ (cfr. la solución del art. 313-c vigente).

Se propone una regla especial en materia de intervención delictiva (inciso $2^{\circ}$ del art. A), de manera que respondan los terceros que cooperan en el ejercicio ilegal de modo relevante (se piensa fundamentalmente en quienes deciden contrataciones en centros de atención al público, por ejemplo).

Se plantea en fin una importante cuestión en el plano de las justificantes (ejercicio legítimo de un derecho u oficio). El punto es atingente a las

\footnotetext{
${ }^{24}$ El Proyecto optaría por la primera alternativa, según se ha visto.

${ }^{25}$ Esto último algo "muy alemán”, si se me perdona la expresión: cfr. \132a StGB.

${ }^{26}$ El Proyecto excluiría la punibilidad de la tentativa de esta figura (simple delito), de modo que la cuestión quedaría zanjada -en el Proyecto- por la exclusión de la mera ostentación de profesión. No se advierte tampoco que dicha conducta quede comprendida por el tipo común de intrusismo del art. 410 del Proyecto.

${ }^{27}$ No se advierte que el Proyecto haya zanjado la cuestión en algún sentido.

${ }^{28}$ Mutatis mutandis, esta sería también la solución del Proyecto, el que en su artículo 573 (regla de concurso agravado en caso de resultados) no contempla referencia al tipo de ejercicio ilegal de profesiones médicas.
} 
Londoño - Bases para una propuesta de reforma en materia de delitos contra la salud...

medicinas alternativas-complementarias. Considérese al respecto el Reglamento Marco en lo pertinente, Decreto No 42 de 2005 del Ministerio de Salud, y los decretos que de él emanan, reconociendo y regulando disciplinas como Acupuntura (Decreto $\mathrm{N}^{\circ}$ 123/2008), Homeopatía (Decreto $\mathrm{N}^{\circ}$ 19/2010) y Naturopatía (Decreto $N^{\circ}$ 5/2013). Otro tanto por lo que se refiere a la medicina tradicional de pueblos indígenas y las prácticas tradicionales de la medicina popular chilena (que con buen criterio el Ministerio de Salud ha optado por no "regular"). Pueden apreciarse las alternativas de reconocimiento de estos espacios de legitimidad en el inciso $3^{\circ}$ del artículo A propuesto a la Comisión. ${ }^{29}$

\section{B.II. Circulación de sustancias o elementos alimenticios, terapéuticos y cosméticos: artículo $B$ de la propuesta (cfr. arts. 543 y 547 del Proyecto; cfr. arts. 313 d y 315 CP)}

Art. B. El que elaborare para expender, expendiere o importare sustancias $\mathrm{O}$ elementos destinados a la ingesta, consumo, administración o aplicación a seres humanos [con finalidades terapéuticas, alimenticias o cosméticas ${ }^{30}$, y que resultaren peligrosos para la salud, ya por su carácter deteriorado, infectado, adulterado o por apartarse de los parámetros de calidad, proporción y composición exigidos por la ley o los reglamentos, será castigado con pena de [**].

[Se entenderá que resultan peligrosos para la salud humana aquellos objetos a que se refiere el inciso anterior y que, bajo condiciones de ingesta, administración o aplicación normales para el tipo de finalidades a ellas asociadas, incrementen el riesgo de provocar, agravar o prolongar [, respecto de un número indeterminado de personas,] afectaciones a la salud superiores o equiparables a aquellas consideradas [menos graves] en el marco de los delitos contra la integridad física $]^{31}$

\footnotetext{
${ }^{29}$ El Proyecto no adoptó una regla especial para hacerse cargo de esta problemática, debiendo asumirse que la discusión se traslada al ámbito de la Parte General, allí donde se reconoce el ejercicio legítimo de un oficio (art. 47 del Proyecto). La belleza sintética y sistemática de una cláusula de autorización como la que suelen incluir nuestras Partes Generales no ofrecerá nunca, en cualquier caso, el grado de seguridad que una cláusula ad hoc, aun si menos bella (y casuística), incorporada en la respectiva Parte Especial. Una cláusula de Parte Especial tiene además la virtud de acercar al intérprete la regulación primaria de sector. Pero con ello digo algo redundante, por cierto, pues justamente en aquel acercamiento está la base de la elogiada seguridad.

30 Una alternativa de redacción en materia de objetos materiales pasaría por adoptar literalmente los conceptos empleados por el Libro IV del CSanitario: [productos alimenticios o farmacéuticos, alimentos de uso médico, cosméticos o cualquier sustancia o elemento destinado al diagnóstico, prevención o tratamiento de enfermedades de seres humanos, así como al reemplazo o modificación de sus anatomías]. Desde ya se advierten dificultades de subsunción relativas a los tabacos y bebidas alcohólicas.

${ }^{31}$ Se propone esta alternativa para el caso de considerarse necesario precisar y calificar los términos de la peligrosidad a que se refiere el inciso primero. Una alternativa a la fórmula de este eventual inciso pasaría por identificar la peligrosidad con una idoneidad probabilística para provocar o prolongar las enfermedades en cuestión, adoptando fórmulas de corte probatorio; fórmulas como "probabilidad prevalente o preponderante"; "más probablemente que no", etc. (por cierto fórmulas idóneas solo para la acreditación del peligro y en ningún caso para la prueba de la causalidad de resultados concretos).
} 
[Por su parte, con pena [*] será sancionado el que elaborare, expendiere o importare las sustancias o elementos a que se refiere el inciso anterior, contraviniendo las disposiciones legales o reglamentarias en materia de información, rotulación o advertencia necesarias para su segura ingesta, administración o aplicación].

\section{Explicación}

En esta importante materia se ha seguido en parte la legislación nacional, así como el proyecto Comisión Foro Penal (arts. 192 y 196), si bien con diferencias de interés.

La formulación (verbos rectores y factores de peligrosidad) da cuenta de una puesta en circulación peligrosa en el marco de contextos productivos u organizados. Lo anterior, en línea con nuestro art. 313-d CP, y distanciándose del modelo del art. $315 \mathrm{CP}$, más propio de un tipo de sabotaje o atentado "desde afuera" del proceso productivo ${ }^{32}$ (como el que sanciona un 314 StGB alemán o un 439 CP italiano). Las formas de sabotaje o de creación de peligro desde afuera de un proceso productivo están llamadas a ser cubiertas por un tipo distinto (art. $G$, inc. primero). ${ }^{33}$

Se refunden en un mismo artículo los objetos materiales de que tratan el art. 313-d y el art. 315 vigentes (medicinales y alimentos), incorporándose el género de los cosméticos (que en el CSanitario son tratados en un plano equivalente al de alimentos y farmacéuticos: cfr. arts. 97 ss.) ${ }^{34}$. Problemático es aquí el concepto de "farmacéutico" (ver alternativa en nota al pie del artículo B), que para el CSanitario incluye el de uso veterinario. El punto merece una discusión y eventual aclaración. La propuesta sugiere excluir aquellos de uso veterinario. ${ }^{35}$

Las formulaciones empleadas para definir los objetos materiales deberían estar en condiciones de asumir un alcance relativamente amplio, comprendiendo desde ya los elementos usados en implantes y transfusiones (sangre por de pronto). ${ }^{36}$ En esto se sigue también la línea del CSanitario (cfr. su art. 101), amén de hacerse cargo de un punto discutido en el contexto español. ${ }^{37}$

\footnotetext{
32 Cfr. supra la nota 15.

${ }^{33}$ En lo grueso, esta decisión fue seguida por el Proyecto, que contempla, por un lado, tipos de responsabilidad por el producto (arts. 543 y ss.) y, por el otro, un tipo de envenenamiento o adulteración "desde afuera", al modo del sabotaje (art. 549).

${ }^{34}$ Esta decisión fue seguida por el Proyecto, que en su art. 543 contempla estos tres objetos materiales.

35 Así también se desprende del art. 543 del Proyecto, limitado a sustancias destinadas a seres humanos.

36 El Proyecto mantuvo esta decisión caracterizando las sustancias típicas como aquellas "destinadas a la ingesta, consumo, administración o aplicación a seres humanos con finalidades terapéuticas, alimenticias o cosméticas".

${ }^{37}$ Cfr. MuÑoz CONDE (2002), p. 616.
} 
Se optó por usar los sustantivos sustancia y elemento en todos los casos. Se asume que ellos satisfacen las exigencias de alcance requeridas. Por sustancia habrá que entender compuestos orgánicos (sólidos y líquidos, por de pronto); elementos resulta una vOz residual. Todo ello se prefirió al más restrictivo sustantivo producto. ${ }^{38}$

En cuanto al verbo expender, se optó por no incluir la habitual referencia a cualquier titulo, simplemente por asumir que no hay razones para interpretarlo de otra manera. Ello, en un contexto en el que no se usan verbos alternativas como "comercializar" o "vender", que puedan llevar a pensar en un sentido diverso para la voz "expender".

Por otra parte, se procura especificar el contexto o causa de la nocividad o aptitud lesiva de las sustancias o elementos (siguiendo en parte la propuesta de la Comisión Foro Penal, en su art. 192). ${ }^{40}$ Como podrá apreciarse, con esta fórmula se despeja - en el sentido de su inclusión - la cuestión relativa a los casos de "falsificación" de sustancias respecto de los parámetros o propiedades exigidos por leyes o reglamentos (algo que, como se vio, es altamente discutible en al art. 315 CP: véase supra la nota 15).

En un inciso $2^{\circ}$ complementario (alternativa en corchetes) se procura definir y calificar el peligro, asegurando su carácter común y acotándolo a aquel peligro idóneo para explicar resultados de lesión de mediana gravedad (punto muy discutible, como podrá advertirse). La fórmula anterior apunta también a asegurar la cobertura de sustancias o elementos cuya idoneidad lesiva se coloca en un plano de causalidad omisiva (aquellos que son peligrosos porque no proporcionan los nutrientes o químicos esperados). ${ }^{41}$

Se incorpora un inciso $3^{\circ}$ también a modo de alternativa (en este caso porque se ofrece no sin vacilaciones del suscrito), para hacerse cargo de un tipo de defecto eventualmente no cubierto por el inciso $1^{\circ}$ (y que posiblemente no merece quedar cubierto por dicho inciso): aquellas sustancias expendidas con déficit informativo, de rotulado, etc. La pena aquí debe ser inferior (si es que se decide en efecto criminalizarlos). Este tipo de defecto corresponde a una de las tres categorías asentadas en la jerga de la product liability del derecho civil (defectos de diseño, defectos de fabricación y defectos de advertencia). ${ }^{42}$

\footnotetext{
${ }^{38}$ El Proyecto mantiene esta decisión en su art. 543, suprimiendo la alternativa "elementos".

${ }^{39} \mathrm{El}$ Proyecto fue del mismo parecer en este punto: cfr. sus arts. 543 y ss.

${ }^{40}$ El Proyecto siguió también esta sugerencia, allí donde se lee, en su art. 543, que las sustancias típicas son aquellas que "resultaren peligrosas para la salud por su carácter deteriorado, infectado o adulterado o por apartarse de los parámetros de calidad, proporción o composición exigidos por la ley o los reglamentos".

${ }^{41}$ Problemático por ejemplo en el ya aludido "caso leche Adn" o "alimento enteral" (supra notas 13 y 15), en el que era la falta de potasio suficiente de la fórmula de la leche la que, bajo un presupuesto de patología pre-existente de quienes la ingerían, habría llevado a los resultados imputados en el juicio.

${ }^{42}$ El Proyecto recogió esta idea, si bien dando lugar a un tipo separado, con relativa menor pena: art. 547.
} 
Un aspecto problemático que recorre esta propuesta y la del art. E, es el relativo al tratamiento de alcoholes y tabacos. No parece haber espacio para ellos en este contexto, siendo el art. E un lugar más adecuado para esos géneros (si bien el punto puede ser discutible). ${ }^{43}$

No se incluyen propuestas que incidan en la regulación del iter criminis (cfr. el inciso $3^{\circ}$ del art. 315, tangencial en la materia), ${ }^{44}$ ni propuestas de restricción de la acción penal pública (cfr. inciso penúltimo del art. 315).

En fin, no ha parecido pertinente hacerse cargo expresamente de hipótesis de suministro de sustancias tóxicas a animales cuyas carnes o productos se destinen al consumo humano, de modo que generen riesgos para las personas (casos clembuterol, dioxina). Se asume que dicha conducta será de todos modos punible en fases de expendio e importación a que se refiere el art. B, más allá de la discusión sobre el alcance de la voz "elaborar" para este tipo de casos. Con ello debería bastar. Ir en una línea como el art. 364.2 CP español de 1995 parece un exceso. ${ }^{45}$ En lo demás podrán resultar aplicables tipos como el 291 CP actual (art. 179 anteproyecto Comisión Foro Penal).

\section{B.III. Figura de omisión propia: art. C de la propuesta (cfr. art. 548 del Proyecto).}

Art. C. Si el responsable de la elaboración, expendio o importación de las sustancia o elementos de que trata el artículo precedente viniese a conocer su peligrosidad en una fase posterior a su elaboración, expendio o importación, deberá sin demora [adoptar las medidas cautelares pertinentes] [dar noticia de ello a la autoridad y a los consumidores], en los casos y bajo las condiciones exigidos por la ley o los reglamentos ${ }^{46}$. La omisión o defectuosa ejecución de dichas medidas será sancionada con la pena de $\left[{ }^{*}{ }^{47}{ }^{47}\right.$

\footnotetext{
${ }^{43}$ El Proyecto no abordó especialmente esta cuestión, hasta donde alcanzo a ver.

${ }^{44}$ Aunque, de otra opinión, cfr. SALAZAR (2015), pp. 318-361. Véase al respecto lo que se dirá infra en nota 48.

${ }^{45}$ Cfr. CP español de 1995, art. 364. 2. "Se impondrá la misma pena al que realice cualquiera de las siguientes conductas: $1 .^{\circ}$ Administrar a los animales cuyas carnes o productos se destinen al consumo humano sustancias no permitidas que generen riesgo para la salud de las personas, o

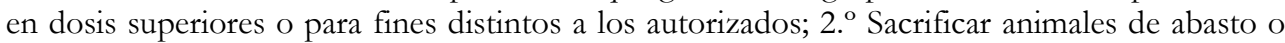
destinar sus productos al consumo humano, sabiendo que se les ha administrado las sustancias mencionadas en el número anterior; $3 .^{\circ}$ Sacrificar animales de abasto a los que se hayan aplicado tratamientos terapéuticos mediante sustancias de las referidas en el apartado $1 .^{\circ} ; 4 .^{\circ}$ Despachar al consumo público las carnes o productos de los animales de abasto sin respetar los períodos de espera en su caso reglamentariamente previstos.

${ }^{46}$ Cfr. art. 46 de la Ley del Consumidor, $\mathrm{N}^{\circ}$ 19.496, infra transcrita, en el cuerpo de este informe.

${ }^{47}$ Redacción alternativa: El responsable de la omisión o defectuosa ejecución de las actuaciones cautelares exigidas por la ley o los reglamentos para los casos de conocimiento subsecuente acerca de la peligrosidad de las sustancias o elementos a que se refiere el articulo anterior, será sancionado con la pena de [*].
} 


\section{Explicación}

Una decisión posiblemente discutible de la propuesta se identifica con este artículo, sin equivalente en nuestro derecho penal vigente ${ }^{48}$. Posiblemente todo el valor de la propuesta esté justamente en su carácter de propuesta; es decir, en asegurarnos un espacio de discusión especial sobre el punto. ${ }^{49}$

Se busca tipificar la conducta de quien omite tomar las medidas de resguardo que la ley y los reglamentos disponen para quien advierte un factor de peligrosidad con posterioridad a su actividad (por cierto tratándose de actividad no dolosa). Traduce en categorías familiares a nuestro ordenamiento, lo que en legislación comparada se conoce como infracción a deberes de recall o retirada de los productos peligrosos (o cuanto menos de suspensión de distribución y advertencia al público)..$^{50}$

$48 \mathrm{Al}$ respecto, pionero entre nosotros, cfr. CONTRERAS (2015), p. 286 (nota 103), reconociendo que las figuras de los artículos 313d, 314 y 315 del CP vigente no permiten dar cobertura a la infracción de deberes de vigilancia, advertencia y retirada, apoyándose por lo demás en la opinión de la propia Corte Suprema, sentada en la ya aludida sentencia del "caso leche ADN" o "del alimento enteral" (SCS, 27.12.2012, Rol No 6831-12). Como se ha adelantado, otra opinión es defendida por SALAZAR (2015), pp. 318-361, argumentando que el inciso $3^{\circ}$ del art. $315 \mathrm{CP}$, entendido como una fórmula de tipificación de la mantención para la venta, "constituye un delito de omisión propia que obliga al destinatario de la misma a realizar las acciones posibles y necesarias de ejecutar para desactivar el riesgo que ha creado con la puesta en circulación de un bien peligroso" (ob. cit. p. 357). La propuesta de Andrés Salazar es sin duda creativa y sugerente, y a sus argumentos puede agregarse una determinada lectura del deber de advertencia que impone el art. 46 de la ley del consumidor, para fabricantes, importadores y distribuidores por igual. Más discutible, sin embargo, es el rendimiento práctico que la propuesta pueda tener (lo que a juicio del suscrito no empaña su mérito teórico). Prescindiendo de la objeción más radical deslizada supra en nota 15 (la idea que de este tipo se acota a conductas de sabotaje, de adulteración desde afuera del proceso productivo; cfr. también infra B.VII), considérese que quien "tiene a la venta en un lugar público" no es normalmente el productor, ni el distribuidor mayorista, sino el distribuidor al detalle. No es en este sin embargo en quien pesan primariamente los deberes cuya infracción se imputaría en sede del inc. $3^{\circ}$ del art. $315 \mathrm{CP}$, ni quien normalmente vendrá a conocer del defecto, subsecuentemente. Esto significa que querrá imputársele el "tener a la venta (al detalle)" al propio productor, si es que se trata de hacerle responder por su omisión (y ya no solo buscar la responsabilidad del vendedor al detalle). Esa imputación es posible, aunque puede enfrentar dificultades (contra las que justamente la propuesta de Salazar debería ofrecer argumentos).

${ }^{49}$ La idea general de la propuesta sería en definitiva recogida por el Proyecto, como art. 548, ampliando su alcance por lo que atañe a los objetos materiales alcanzados (no solo alimentos, medicamentos y cosméticos, sino también otras sustancias peligrosas), modulando la pena dependiendo de la clase de objeto de que se trate y dejando a salvo la responsabilidad por los resultados lesivos que se ocasionaren.

${ }^{50}$ Por lo que se refiere a la legislación federal de EEUU, cfr. 15 U.S.C \$3501 en material de recall: "If the Secretary determines, based on information gathered through the reportable food registry under section $350 f$ of this title or through any other means, that there is a reasonable probability that an article of food (other than infant formula) is adulterated under section 342 of this title or misbranded under section 343 (w) of this title and the use of or exposure to such article will cause serious adverse health consequences or death to bumans or animals, the Secretary shall provide the responsible party (as defined in section $350 f$ of this title) with an opportunity to cease distribution and recall such article". A su turno, el 15 U.S.C \ 333 f) 2), a), dispone: "Any person who introduces into interstate commerce or delivers for introduction into interstate commerce an article of food that is adulterated within the meaning of section 342 (a)(2)(B) of this title or any person who does not comply with a recall order under section $350 \mathrm{l}$ of this title shall be subject to a civil money penalty of not more than \$50,000 in the case of an individual and \$250,000 in the case of any other person for such introduction or delivery, not to exceed $\$ 500,000$ for all such violations adjudicated in a single proceeding". 
Sobre el particular puede considerarse el deber de advertencia a la autoridad y a los consumidores que pesa sobre el fabricante, importador o distribuidor en conformidad al art. 46 de la ley del Consumidor, No 19.496. En efecto, esta norma dispone que "todo fabricante, importador o distribuidor de bienes o prestador de servicios que, con posterioridad a la introducción de ellos en el mercado, se percate de la existencia de peligros o riesgos no previstos oportunamente, deberá ponerlos, sin demora, en conocimiento de la autoridad competente para que se adopten las medidas preventivas o correctivas que el caso amerite, sin perjuicio de cumplir con las obligaciones de advertencia a los consumidores señaladas en el artículo precedente".

La propuesta repercute también en la imputación de resultados, sugiriéndose una penalidad menor para ese evento (art. H inciso $2^{\circ}$ ).

\section{B.IV. Figura de intrusismo en elaboración y expendio de medicinales. Mendacidades en contextos de autorización de la actividad: Art. D de la propuesta (cfr. art. 544 del Proyecto)}

Art. D. El que, sin contar con la competente autorización, elaborare, expendiere o importare sustancias o elementos terapéuticos [o cosméticos], será sancionado con pena [*], a menos que se configuraren los presupuestos del [inciso primero del] artículo B, caso en el cual la pena será de $[* * *]$.

Con pena [*] será sancionado quien, en el marco de un proceso de autorización para el desarrollo de las actividades a que alude el inciso precedente, hubiere aportado antecedentes falsos, por sí mismos relevantes o idóneos para la obtención de una decisión favorable de la autoridad.

\section{Explicación}

El artículo propuesto contempla dos figuras penales. En cuanto a la primera, que busca sancionar el intrusismo en materia de elaboración, expendio e importación de medicamentos (y cosméticos, en su caso), se inspira en la propuesta del art. 194 de la Comisión Foro Penal. Se advierte en este punto un vacío en nuestra legislación penal (salvo que se nos escape la existencia de un tipo en legislación especial). Nótese que intrusismos en profesiones y en actividades como mataderos son delictivas. Esta forma de intrusismo no parece estar de ningún modo por debajo de ellas. El 313-d CP solo contempla la clandestinidad como agravación de pena, en un contexto dado de peligrosidad.

La limitación a los géneros referidos (sustancias terapéuticas, en principio) parece adecuada, no siéndolo en cambio su extensión al campo de los alimentos y bebidas (con el riesgo de criminalizar el comercio ambulante de alimentos y todo el género de producción artesanal que las más de las veces hace muy felices a las personas...) 
$\mathrm{El}$ inciso $2^{\circ}$ propuesto incluye una figura sin correlatos inmediatos en nuestra legislación, destinada a sancionar mendacidades en contextos de autorización para elaborar o expender los artículos en cuestión. La inspiración se encuentra en los modelos estadounidenses consultados (cfr. supra derecho comparado), muy dados a incluir figuras de este género. ${ }^{51}$

\section{B.V. Circulación de otras sustancias peligrosas, defectuosas: art. E de la propuesta (cfr. arts. 545 y 546 del Proyecto; ${ }^{52}$ art. 314 CP)}

Art. E. El que elaborare, envasare, expendiere, importare, almacenare o manipulare sustancias o elementos peligrosos para la salud humana, ${ }^{53}$ distintos de los mencionadas en los artículos precedentes, contraviniendo las disposiciones legales o reglamentarias establecidas en atención al tipo de riesgo de que se trate, será sancionado con la pena de [**] [, en la medida que con su conducta hubiere puesto en peligro la salud de un número indeterminado de personas]. ${ }^{54}$

Con [igual] pena será sancionado el que, contraviniendo las disposiciones legales o reglamentarias establecidas en atención al tipo de riesgos de que se trate, elaborare para expender, expendiere o importare, elementos destinados a resguardar de riesgos de muerte o grave enfermedad, intrínsecos o derivados de actividades productivas, extractivas o de servicios, en la medida que con su conducta hubiere puesto en peligro la salud de un número indeterminado de personas.

Lo dispuesto en el [artículo C] recibirá también aplicación en los supuestos a que se refiere este artículo.

\footnotetext{
${ }^{51}$ Solo la primera de las figuras propuestas (intrusismo en elaboración) sería recogida como tal por el Proyecto, como art. 544, con modificaciones. No se acogió en cambio la figura especial de mendacidad. La aportación de antecedentes falsos podría eventualmente quedar cubierta por los tipos comunes de falsedad previstos por el Proyecto, especialmente su art. 407, que propone sancionar la entrega de información falsa o incompleta a la autoridad.

${ }^{52}$ El Proyecto recogería la propuesta en términos generales, como arts. 545 y 546, aunque con modificaciones relevantes, en general hacia su ampliación: optando por rechazar una fórmula que puede interpretarse como de peligro concreto; extendiendo algunos verbos rectores (transportar, tratar, abandonar); y acogiendo, con mejoras, la propuesta alternativa del informe, incluyendo así los objetos destinados a la manipulación por infantes (como numeral $3^{\circ}$ del art. 546).

53 Cfr., entre otros, Reglamentos del Ministerio de Salud Nos 144/85 (solventes orgánicos nocivos para la salud); 105/98 (pesticidas domésticos), 148/03 (residuos peligrosos), 158/03 (sobre tolueno en juguetes), 114/05 (seguridad de los juguetes); y Res. Exenta $N^{\circ} 714 / 02$, que aprueba lista de sustancias peligrosas para la salud.

54 Propuesta complementaria y alternativa al inciso segundo que abajo se propone: "Para los efectos de esta disposición, se reputarán igualmente peligrosos para la salud humana aquellos elementos destinados a su uso corriente por infantes [, las bebidas alcohólicas, los tabacos] y todos aquellos elementos destinados a resguardar a seres humanos de riesgos de muerte o grave enfermedad, intrínsecos o derivados de actividades productivas, extractivas o de servicios".
} 


\section{Explicación}

La propuesta se basa en el actual $314 \mathrm{CP}$, siguiendo también el modelo de la Comisión Foro Penal (art. 193). Se trata en general de tipificar conductas que incrementan el riesgo de sustancias peligrosas para la salud humana (intrínsecamente o por sí mismas, si bien la propuesta innova en la inclusión de objetos relevantes por el tipo de riesgos que buscan prevenir o bien por su destino para el uso de niños).

Se procura precisar la fuente contextual del peligro incremental (adicional al intrínseco al objeto), ofreciéndose como alternativa complementaria una fórmula restrictiva que lo acercaría a un delito de peligro concreto.

En cuanto a los objetos materiales, hay novedades, en la medida que se incluye un inciso $2^{\circ}$ destinado a incluir entre los objetos aquellos que cumplen fines de resguardo frente a riesgos propios o derivados de actividades productivas, extractivas o servicios (y solo para dichos contextos). Se entra así en la esfera de la protección de la seguridad en el trabajo. El riesgo de ampliación es significativo con esta fórmula. De todos modos, desde un punto de vista de lesividad, no se ven serias razones para oponerse a un tipo semejante: ¿la venta de ácidos en envases inadecuados es punible y no lo es la fabricación de trajes anti-radiación defectuosos, o la de máscaras que solo en apariencia protegen de los riesgos de silicosis en las minas, etc.? Con todo, el punto merece una discusión importante, considerando los riesgos de pérdida de control aplicativo de una cláusula semejante. Una alternativa de redacción que también se hace cargo del punto anterior se incluye en nota al pie 54 , a la que se reenvía.

En fin, en este ámbito podrá discutirse la situación de alcoholes, tabacos y juguetes (véase propuesta alternativa en nota 54). Cabe tener presente que el art. 42 de la ley $\mathrm{N}^{\circ} 18.455$ tipifica situaciones afines en materia de alcoholes, reenviando en sus penas justamente al art. 314 CP (véase referencia en nota en art. M derogatorio). Por lo que se refiere al tabaco, existen disposiciones puramente infraccionales en el art. 16 de la ley $\mathrm{N}^{\circ} 19.419$, si bien reconociéndose como no excluyentes de la responsabilidad penal que correspondiere (presumiblemente el propio art. $314 \mathrm{CP}$ ). ${ }^{55}$ En cuanto a los juguetes para infantes -que en principio no quedan comprendidos en el actual art. $314 \mathrm{CP}$ ni en la propuesta de art. E- su situación bien merece una mirada. Se ha advertido la existencia de detalladas regulaciones reglamentarias sobre el

\footnotetext{
${ }^{55}$ Artículo 16 de la ley No 19.419: "La infracción de las disposiciones de la presente ley será sancionada en conformidad a las reglas siguientes: 1) Multa de 3 a 50 unidades tributarias mensuales, y de 30 a 300 unidades tributarias mensuales, si la infracción es cometida por una persona natural o jurídica perteneciente a la industria tabacalera, por la venta, la compra para vender, la comercialización en cualquier forma, la distribución, el transporte y el almacenaje de productos de tabaco, de cualquier forma, clase o naturaleza, que no cumplan con las obligaciones legales en materia sanitaria, aduanera, tributaria y de propiedad intelectual. En estos casos, la multa procederá sin perjuicio de las sanciones penales que pudieren corresponder. Además, en caso de reincidencia, se decretará la clausura del establecimiento, comercio o lugar donde se hubiere cometido la infracción por un período de quince días".
} 
punto (véase la nota respectiva en el artículo propuesto), sin que en todo caso se advierta su criminalización a título de delito de peligro.

\section{B.VI. Regla en materia de intervención delictiva en contextos de actividad en entes colectivos: Art. F}

Art. F. Se reputará que realiza las conductas descritas en los artículos [precedentes de este apartado] y responderá por consiguiente con la penas previstas para el autor de los respectivos delitos, todo aquél que, en calidad de [socio principal, director, ejecutivo principal, liquidador, administrador o gerente ${ }^{56}$ de una [entidad / personas jurídica] dedicada o relacionada al giro de que se trate, ejecute, ordene, autorice o tolere cualquier acto o práctica que contribuya a la configuración del [peligro / hecho punible]. En dicho supuesto, los demás agentes, internos o no a la [entidad / personas jurídica], que ejecuten o validen cualquier acto o práctica que contribuya a la configuración del [peligro / hecho punible], responderán con las penas previstas para los intervinientes. Con todo, de haber actuado estos sin el conocimiento de los mencionados superiores [socio principal, etc.], responderán con las penas previstas para los autores. ${ }^{57}$

El funcionario público competente que validare las actuaciones de los particulares punibles en conformidad al inciso precedente, o no adoptare las medidas de su competencia para denunciar o impedir las conductas sancionadas en los artículos [B y E de este apartado], responderá con las penas previstas para los [intervinientes] de dichos delitos. [De igual modo responderá el particular que hubiere otorgado certificaciones de idoneidad para las sustancias o elementos de que se trate].

\section{Explicación}

Los problemas que le dan lugar, sus propósitos y sus consecuencias serán evidentes para la Comisión, lo que ahorra mayores comentarios, más allá de afirmar que procura facilitar la imputación de responsabilidad individual en contextos organizados, como típicamente lo son las empresas con incidencia en la elaboración y expendio de los productos o sustancias de que tratan los artículos precedentes.

Se propone para ello una perspectiva top-down, de modo que la responsabilidad principal (autoría) se radique en los agentes con poder de dirección (supuesta su intervención culpable, naturalmente). Por cierto, la forma de autoría más discutible en este contexto es aquella que coincide con la mera "tolerancia" de un hecho ajeno (elevada a autoría en atención al carácter esencial para la configuración del hecho punible de aquel poder-de-evitación-noejercido). La responsabilidad de los subordinados-ejecutantes re-emerge como

\footnotetext{
${ }^{56}$ Cfr. artículos 12 y 68 de la ley $\mathrm{N}^{\mathrm{o}} 18.045$.

${ }^{57}$ Cfr. 15 U.S.C. $\int 2070$ b (Consumer Product Safety Act), infra transcrito, el que parcialmente se siguió aquí. Cfr. igualmente el infra transcrito art. 228 del Anteproyecto Comisión Foro Penal.
} 
responsabilidad principal (autoría) solo allí donde hubieren actuado de manera autónoma o inconsulta. ${ }^{58}$

Para la formulación de esta propuesta se tuvo a la vista la norma del 15 U.S.C. \ 2070 b (= Consumer Product Safety $A c t,{ }^{59}$ de interés en cuanto explicita la relevancia de actuaciones que solo en parte constituyen la infracción punible), así como el art. 228 del proyecto Comisión Foro Penal ${ }^{60}$ (si bien la presente propuesta obedece a un modelo en principio más restrictivo de imputación, pues bien podría interpretarse el art. 228 como una norma tolerante a una imputación de responsabilidad puramente objetiva). Para la terminología relativa a los "superiores", se ha adoptado el modelo de la ley $\mathrm{N}^{\circ}$ 18.045, concretamente sus arts. 12 y 68.

Como inciso $2^{\circ}$ se propone una regla para las intervenciones de funcionarios públicos y para los particulares que certificaren mendazmente, sobre la que se expuso supra en la Fundamentación general.

En fin, más allá de sus méritos, se asume que la propuesta de art. F se tornaría innecesaria sobre la base de una regla ad hoc de Parte General, que posiblemente la Comisión quiera contemplar. ${ }^{61}$

\footnotetext{
${ }^{58}$ Este párrafo explicativo no es original del informe. Ha sido incorporado por el suscrito en el marco de la reedición del texto para su publicación en este medio. En lo que sigue de este subapartado se ha mantenido la explicación original, si bien con ciertas modificaciones de estilo o con propósitos de aclaración.

5915 U.S.C. \2070: “(a) Violation of section 2068 of this title is punishable by- (1) imprisonment for not more than 5 years for a knowing and willful violation of that section; (2) a fine determined under section 3571 of title 18; or (3) both. (b) Any individual director, officer, or agent of a corporation who knowingly and willfully authorizes, orders, or performs any of the acts or practices constituting in whole or in part a violation of section 2068 of this title shall be subject to penalties under this section without regard to any penalties to which that corporation may be subject under subsection".

${ }^{60}$ Art. 228. "Para los efectos de lo dispuesto en este Título, se entenderán como responsables o administradores de una empresa, proyecto o actividad los que lo sean de hecho o de derecho y, especialmente, sus representantes, directores y gerentes. // Respecto de estas personas, y sin perjuicio de las reglas generales, se estimará suficiente prueba para eximirlas de responsabilidad penal por alguna de las conductas sancionadas en este Título, la de haberse opuesto al acto u omisión que constituye el delito, intentando seriamente evitar su realización; o mediante el establecimiento previo de medidas de control administrativo que sus subordinados hubiesen infringido, sin su conocimiento o sin que les fuese posible evitarlo, por provenir de acciones de sabotaje $\mathrm{u}$ otras intervenciones de terceros de similares características.

// En el caso de los directores o gerentes de una persona jurídica, su oposición al acto que constituye el delito, podrá acreditarse con la sola exhibición de las actas correspondientes a la sesión del directorio en que se decidió su realización. // En caso de sabotaje o intervención de terceros de similares características, se sancionará con las mismas penas previstas para los responsables o administradores de la empresa, proyecto o actividad, a quienes lo sean del sabotaje o la intervención de que se trate".

${ }^{61}$ En definitiva la Comisión no incorporaría una propuesta como la aquí formulada, ni para este apartado, ni como regla especial de la Parte General (por cierto la regla de actuación en lugar de otro del art. 40 responde a un problema distinto, de tipicidad). Hasta donde alcanzo a ver, la cuestión quedaría entregada a los criterios generales, posiblemente en el ámbito de la coautoría (art. 36 del Proyecto), dependiendo del alcance que se dé a las fórmulas de equivalencia y coordinación allí desarrolladas.
} 


\section{B.VII. Figura de sabotaje vía envenenamiento de sustancias y diseminación de gérmenes patógenos: art. $\mathrm{G}$ de la propuesta (cfr. arts. 549 y 550 del Proyecto; arts. 315 y 316 CP)}

Art. G. El que fuera de los casos previstos en los artículos [precedentes de este apartado], envenenare, infectare o adulterare aguas, sustancias o elementos destinados al consumo público, de modo que resulten peligrosos para la salud humana, será sancionado con pena [**]

Con [igual] pena será sancionado el que diseminare gérmenes patógenos idóneos para producir una enfermedad en la población. ${ }^{62}$

\section{Explicación}

Se propone contemplar una figura de peligro común no enmarcada en procesos productivos, ${ }^{63}$ parcialmente equivalente a nuestros actuales arts. 315 y $316 \mathrm{CP}$, y en línea con el $\$ 314$ StGB alemán y los arts. 438-439 CP italiano.

El inciso primero aborda aspectos cubiertos por el art. 315 vigente. Solo una construcción como la adoptada por nuestro CP -que la coloca fuera de los más modernos tipos de responsabilidad por el producto- puede explicar su asociación a un delito terrorista (como es el caso bajo el régimen actual, bajo el art. 2 , num. $1^{\circ}$ de la ley $\left.{ }^{\circ} 18.314\right)$.

Otro tanto puede decirse del inciso $2^{\circ}$, que se llena de contenido con la fórmula del actual art. 316 (diseminación de gérmenes patógenos).

Se ofrece como alternativa de complemento la posibilidad de acotar la figura del inciso $2^{\circ}$ con un elemento de intención trascendente (como hace el art. $316 \mathrm{CP})$. Ello no parece en todo caso indispensable.

La redacción del inciso $1^{\circ}$ parecería sugerir una forma de peligro concreto (aunque ello no es claro), a diferencia de la más clara idoneidad requerida para el inciso $2^{\mathrm{o}} .^{64}$

\footnotetext{
${ }^{62}$ Una variante pasaría por reforzar la tipicidad subjetiva con un elemento de intención trascendente, asociado a la producción de enfermedades en la población, similar al del art. 316 $\mathrm{CP}$ vigente.

${ }^{63}$ Véase supra nota 15.

${ }^{64}$ Hizo bien la Comisión en reformular la propuesta exigiendo idoneidad (fórmula de peligro abstracto-concreto), descartando la redacción propuesta que, para el caso del envenenamiento, infección o adulteración, parecía exigir un (injustificadamente restrictivo) peligro concreto. La Comisión siguió en lo demás la idea general de la propuesta, fraccionándola en dos disposiciones (arts. 549 y 550 del Proyecto) y mejorándola allí donde distinguió dos niveles de gravedad del peligro para el caso de envenenamiento, infección y adulteración, con las consecuencias penológicas del caso.
} 


\section{B.VIII. Regla especial de pena (y solución del concurso) para casos de resultados de lesión o muerte: Art. $\mathrm{H}$ de la propuesta (cfr. art. 317 inc. $1^{\circ} \mathrm{CP}$ )}

Art. H. Si de las conductas de que tratan las disposiciones [B, E y G de este apartado], se derivaren afectaciones a la vida o integridad física de una o más personas, nacidas o que estuvieren por nacer, se aplicarán las siguientes penas:

1. La pena de [******], tratándose de resultados de muerte de una o más personas, en la medida que ellos fueren imputables a título de dolo, y la pena de [***], si los resultados fueren imputables a título de imprudencia.

2. Etc. (se propone incluir dos numerales más, con tramos de pena diferenciados para (1) resultados de malformaciones o lesiones [de grave entidad]; y (2) resultados de lesiones [de mediana o leve entidad].

Tratándose de resultados derivados de la conducta a que se refiere el [artículo C], se aplicarán las penas mencionadas arriba, reducidas en $[\ldots]^{65}$

\section{Explicación $^{66}$}

Por una solución penológica ad hoc optó el Anteproyecto Comisión Foro Penal en definitiva (pese a que en una primera versión se incluía una calificación en los entonces arts. 155, 156 y 159; las razones para tal giro no constan en las actas del Anteproyecto). Es también la solución adoptada por el CP español de 1995, hasta donde se alcanzó a ver, así como, parcialmente, la del CP italiano (solo para las figuras de adulteración y falsificación: arts. 440 ss.; no así para el caso de muerte, respecto de las figuras de envenenamiento y epidemia: arts. 438 y 439). En una línea similar, el art. 313-c CP opta por aseverar el concurso, sin proponer una solución penológica (que asumimos será la del $75 \mathrm{CP}$ ). Esa solución es coincidente con la que el CP original ofrecía para estos delitos (art. 319, a instancias del comisionado Reyes).

\footnotetext{
${ }^{65}$ Puede obviarse la distinción entre resultados imputables a título de dolo o imprudencia, incluyendo una cláusula de subsidiariedad expresa, del tipo: “....salvo que por los solos delitos de resultados corresponda aplicar una pena superior a la prevista en este título". Como puede advertirse, la preocupación subyacente a la distinción es la de no infravalorar la pena para casos en los que los propios resultados puedan reputarse dolosos (si bien muy extraño en el ámbito de la producción autorizada, no puede descartarse del todo).

${ }^{66} \mathrm{La}$ Comisión no siguió esta propuesta, que procuraba una solución penológica ad hoc (autónoma) para el caso de concurso entre los respectivos delitos de peligro y su concreción en resultados. Se prefirió en su lugar una fórmula de concurso agravado. En efecto, la Comisión consideró una disposición común para los delitos del Título XIV (art. 573 del Proyecto), que contempla una importante agravación para la fijación de la pena de los delitos de resultado (muerte y lesiones graves) causados con ocasión de los delitos de peligro de que trata este apartado; lo anterior, sin perjuicio de someter el delito de peligro y los delitos de resultado (así agravados) a las reglas generales en materia de concurso, con reenvío al art. 82 y ss. del Proyecto (de especial interés su artículo 87, en materia de pluralidad de resultados atribuibles a imprudencia o a dolo e imprudencia).
} 
Como se sabe, una regla especial de pena para el caso de resultados es, por otra parte, la que contempla el art. $317 \mathrm{CP}$, con toda la ambigüedad del caso $^{67}$ y distanciándose de la regla que para el art. 313-a contempló el propio legislador de 1969 a través del 313-c. Es también, hasta donde se alcanza a ver, el caso del StGB alemán en su $\ 314$, con referencia a los incisos 2 a 4 del $\$ 308$.

La propuesta de art. $\mathrm{H}$ distingue ámbitos de delitos de peligro base (con pena inferior para el caso de resultados derivados de las conductas omisivas del art. C), así como imputaciones de resultados a título doloso o imprudente. Este último aspecto puede resultar particular: en efecto, se asume que la normalidad de los casos corresponderá a resultados imputables a imprudencia, pero no puede descartarse una imputación a título doloso (dolo eventual al menos, o como quiera que este se defina y sancione en la propuesta final de la Comisión). ${ }^{68}$

La propuesta es por cierto compatible con una cláusula de subsidiariedad expresa, siempre útil para evitar incongruencias penológicas.

Sujetos pasivos de los resultados comprendidos por la cláusula son tanto personas nacidas como personas no nacidas. ${ }^{69}$

En fin, toca mencionar la pertinencia de una regla -aquí no adoptada- en materia de prueba de la causalidad de resultados derivados de productos defectuosos o peligrosos. Una regla semejante es considerada por el anteproyecto Comisión Foro Penal en su art $232,{ }^{70}$ en principio sobre la base de referentes de causalidad epidemiológica. El punto es complejo -e interesantísimo- pero no resulta posible fundamentarlo aquí. Se reenvía a la detallada exposición efectuada por Héctor Hernández -crítico de la propuesta- en su trabajo "El problema de la "causalidad general" en el derecho penal chileno (con ocasión del art. 232 del Anteproyecto de Nuevo Código Penal)" ${ }^{71}{ }^{72}$

\footnotetext{
${ }^{67}$ Para una síntesis de las diversas posiciones de la doctrina nacional en cuanto a su alcance, cfr. Londoño, "Comentario al art. 317 del Código Penal Chileno", todavía inédito.

${ }^{68} \mathrm{Ni}$ el Anteproyecto ni el Proyecto se comprometieron con una definición general de dolo.

${ }^{69}$ El Proyecto no siguió en esto la propuesta (cfr. art. 573 del Proyecto).

${ }^{70}$ Anteproyecto de Comisión Foro Penal, art. 232: "Sin perjuicio de las reglas generales, podrá tenerse por probado que la operación de un proyecto o actividad ha producido efectivamente lesiones graves o la muerte de una o más personas determinadas, si se cumplen los siguientes requisitos: a) Que exista prueba de que una o varias personas determinadas estuvieron expuestas al peligro producido por el proyecto o actividad, con anterioridad a sus lesiones o muerte; b) Que exista prueba pericial que aporte una explicación general sobre los procesos biológicos, químicos o físicos que desencadenan en las personas la exposición al peligro de que se trate; y c) Que exista prueba pericial de que en las personas lesionadas o muertas se desencadenaron similares procesos a los mencionados en la letra anterior, después de su exposición al peligro de que se trate".

${ }^{71}$ HERNÁNDEZ (2006), p. 1-33.

${ }^{72} \mathrm{La}$ Comisión optó por no incorporar una regla en materia de prueba de la causalidad, distanciándose en esto del Anteproyecto Comisión Foro Penal.
} 


\section{B.IX. Desistimiento o arrepentimiento eficaz: art. I de la propuesta}

Art. I. Quedará exento de pena por los delitos de peligro de este apartado [o se beneficiará con una rebaja en [...] el responsable que abandonare voluntariamente la prosecución de su actuar o de cualquier modo eficaz conjurare el peligro creado. La pena de comiso procederá igualmente en estos casos.

\section{Explicación $^{73}$}

Solo a modo de bosquejo se ofrece este artículo, con el ánimo de generar la discusión. Sus ventajas político criminales parecen evidentes en el plano teórico, más allá del escepticismo que podamos abrigar por lo que se refiere a su aplicabilidad en concreto. Se siguió en parte el modelo del \$314-a StGB alemán, sobre arrepentimiento eficaz.

\section{B.X. Responsabilidad a título de imprudencia: art. J de la propuesta (cfr. 317 inc. $2^{\circ} \mathrm{CP}$; art. 551 del Proyecto)}

Art. J. El que por imprudencia diere lugar a [o interviniere en] las conductas previstas en los artículos [B, C, E y G] responderá [con las penas que en cada caso se indican, rebajadas en $\{\ldots\}]$ / Alternativa:

1. Con la pena de [...] en el caso de las conductas previstas en el artículo $[\ldots]$

2. Con la pena de [...] en el caso de las conductas previstas en el artículo [...]

3. Con la pena de [...] en el caso de las conductas previstas en el artículo [...]

Mientras más se empeñaba el suscrito en mejorar la propuesta en este punto, más se asomaban las dudas, hasta casi cederse a la tentación de suprimirla, declarando que un mejor sistema es aquél que resuelve el problema desde la PG (o que no lo resuelve...).

\section{Explicación $^{74}$}

Seguramente tocará discutir su alcance (qué conductas ha de comprender) y eventualmente el estándar de culpa exigido. En lo demás se sigue el modelo del CP vigente (art. 317 inc. $2^{\circ}$ ), siendo también de posible utilidad una técnica de cláusula ad-hoc para cada figura (como lo hace el Anteproyecto Comisión Foro Penal, art. 192 ss.).

\footnotetext{
${ }^{73}$ La Comisión no adoptó una fórmula como la propuesta para estos delitos, quedando el problema cubierto por las reglas generales en materia de desistimiento (art. 33 del Proyecto).

${ }^{74} \mathrm{La}$ Comisión acogió la idea tras la propuesta, incorporándose como art. 551 del Proyecto. Se disponen tres tramos de penalidades en orden decreciente, para los delitos de sabotaje, de responsabilidad por el producto y de infracción al deber de rotulación y advertencia. No se dio en cambio cobertura al tipo de omisión (art. C de la propuesta y 548 del Proyecto).
} 


\section{B.XI. Omisión de notificación de enfermedades y brotes infecciones de notificación inmediata: art. $\mathrm{K}$ de la propuesta (art. 552 del Proyecto)}

Art. $\mathbf{K}^{75}$ El profesional de la salud o encargado de un centro de atención médica que omitiere dar cuenta a la autoridad sobre la existencia de un posible caso de enfermedad o causa infecciosa, que viniere a conocer en el desempeño de sus funciones y respecto de la cual las leyes o reglamentos exigieren notificación inmediata, será sancionado con pena $\left.{ }^{*}\right]$. Dicha sanción solo se impondrá en la medida que se demostrare efectivo el brote de la enfermedad o causa infecciosa en cuestión.

En los mismos términos será sancionada la autoridad que, tomando conocimiento de la notificación a que se refiere el inciso precedente, no adoptare las providencias o medidas requeridas por la leyes y reglamentos para dicho evento.

Si las conductas a que se refieren los incisos anteriores solo pudiere imputarse a título de imprudencia, se aplicará la pena $[<*]$.

\section{Explicación $^{76}$}

La propuesta no tiene correlato en el derecho penal nacional, siendo hoy sancionable a título meramente administrativo en virtud del Reglamento $\mathrm{N}^{\circ}$ 158 de 2004 del Ministerio de Salud, sobre notificación de enfermedades transmisibles de declaración obligatoria, en relación con el art. 21 CSanitario.

Para su elevación a conducta típica se ha seleccionado solo el caso de omisión de notificación de aquellas enfermedades que lo requieren con inmediatez, conforme al art. $1^{\circ}$ del citado Reglamento, ${ }^{77}$ incluyéndose una condición objetiva de punibilidad (que la enfermedad o foco se revelen reales).

\footnotetext{
75 Cfr. art. 21 CSanitario y Reglamento No 158 de 2004 del Ministerio de Salud, sobre notificación de enfermedades transmisibles de declaración obligatoria.

${ }^{76} \mathrm{La}$ Comisión acogió la propuesta en términos muy similares, más tarde art 552 del Proyecto, suprimiendo la hipótesis de responsabilidad a título de imprudencia.

77 Art. $1^{\circ}$ del Reglamento $N^{\circ}$ 158/2004: “Se considerarán enfermedades de notificación obligatoria las que a continuación se indican, con su correspondiente periodicidad: a) De Notificación Inmediata: La sospecha de casos de Botulismo, Brucelosis, Carbunco, Cólera, Dengue, Difteria, Enfermedad invasora por Haemophilus influenzae, Enfermedad Meningocócica, Fiebre Amarilla, Fiebre del Nilo Occidental, Infecciones Respiratorias Agudas Graves (incluidas las neumonías que requieren hospitalización), Leptospirosis, Malaria, Meningitis Bacteriana (incluida enfermedad Meningocócica), Peste, Poliomielitis, Rabia humana, Sarampión, SARS, Síndrome Pulmonar por Hantavirus, Triquinosis, y Rubeóla. // La ocurrencia de toda agrupación de casos relacionados en el tiempo y en el espacio, donde se sospeche una causa infecciosa transmisible, incluidos los Brotes de Enfermedades Transmitidas por Alimentos. // La ocurrencia de fallecimientos de causa no explicada, en personas previamente sanas, cuando se sospeche la presencia de un agente infeccioso transmisible".
} 
Se asume que la propuesta es altamente discutible, desde ya porque presenta estructurales problemas en el campo probatorio (el error de tipo será aquí la orden del día, siendo la prueba de su evitabilidad algo tampoco fácil).

Se incluye en fin una hipótesis que sanciona a la autoridad encargada.

\section{B.XII. Mataderos Clandestinos: Art. L de la propuesta (cfr. art. $3^{\circ}$ de la ley $\mathbf{N}^{\circ}$ 11.564)}

Art. L. El responsable o administrador de un matadero clandestino, el que ponga o envíe animales para su beneficio allí, el responsable o administrador del transporte de los productos del matadero clandestino y el que lo sea de su expendio, será sancionado con pena [...].

\section{Explicación $^{78}$}

Con ligera adaptación se toma la propuesta del anteproyecto Comisión Foro Penal (art. 197), a su vez una adaptación del art. $3^{\circ}$ de la ley $\mathrm{N}^{\circ} 11.564$ de mataderos clandestinos (véase nota al pie en art. M derogatorio). En el mencionado anteproyecto solo se deja sin cobertura expresa la letra c) de aquella disposición (creemos que con buenas razones).

\section{B.XIII Derogaciones: art. $M$ de la propuesta}

Art. M. Deróguense las siguientes disposiciones: arts. 42, 43 y 44 de la ley 18.455 (alcoholes nocivos y otros); ${ }^{79}$ art. 170 de la ley 16.464 (alimentos nocivos) ${ }^{80}$; arts. 3 y 4 de la ley 11.564 (mataderos clandestinos) $^{81}$, art. 27 ley 17.164 (intrusismo-tecnólogos médicos), art.

\footnotetext{
${ }^{78}$ La Comisión acogió la propuesta, más tarde concretada como art. 553 del Proyecto.

${ }^{79}$ Ley $\mathrm{N}^{\mathrm{0}}$ 18.455, Art. 42. "El que elaborare productos utilizando alcoholes no etílicos y los destine a la bebida, será sancionado con la pena privativa de libertad establecida en el artículo 314 del Código Penal.

En igual pena incurrirá el que elaborare productos empleando tratamientos o aditivos prohibidos o en una forma distinta a la autorizada, que conviertan al producto en tóxico o dañino para la salud y los destine a la bebida. // Al que sin ser elaborador comprare para vender los productos a que se refieren los incisos anteriores, y los destinare a la bebida, se le aplicará la misma pena que a este. // Se presumirá que un producto se destina a la bebida cuando se expone, ofrece o pone a disposición de terceros en cualquier forma, sin que se advierta de manera destacada en los envases o etiquetas que el producto no es apto para la bebida. // Además de la pena indicada en los incisos precedentes, se aplicará a los infractores una multa de 25 a 200 unidades tributarias mensuales. // Art. 43.- Los que contravinieren algunas de las medidas señaladas en el inciso primero del artículo 53 serán sancionados con la pena de presidio menor en sus grados mínimo a medio. Se les aplicará, además, una multa de 15 a 150 unidades tributarias mensuales. // Art. 44.- El que otorgare certificados de potabilidad respecto de los productos a que se refiere esta ley y que fueren tóxicos o nocivos para la salud será sancionado con la pena de reclusión menor en sus grados mínimo a medio y multa de 15 a 150 unidades tributarias mensuales".

${ }^{80}$ Ley $\mathrm{N}^{\mathrm{0}} 16.464$ de 1966, art. 170. "Las personas que produzcan o vendan artículos alimenticios adulterados maliciosamente, serán castigados con la pena de presidio menor en cualquiera de sus grados, sin perjuicio de las sanciones administrativas procedentes".

${ }^{81}$ Ley No 11.564 de 1954, Art. Artículo 3․ "Sufrirán la pena de presidio menor en su grado medio a máximo o multa de once a quince unidades tributarias mensuales, o ambas
} 
25 ley 17.033 (intrusismo-psicólogos); art. 36 DFL 1 de 1970 (intrusismo-kinesiólogos).

Nota: se da además por descontada la derogación de las siguientes faltas del CP vigente: $\mathrm{N}^{\circ}$ s 7 y 8 art. 494 (despacho de medicamento sin receta y ejercicio ilegal de medicina y otras afines) y $\mathrm{N}^{\circ}$ s 19,20 y 22 art. 496 (disposición no reglamentaria de animales muertos, objetos insalubres y desperdicios). Otro tanto cabe decir respecto al $313 \mathrm{~b}$ del CP.

\section{Explicación}

El punto no requiere mayor explicación, remitiéndose al propio artículo, el que incluye en nota al pie los textos de algunas de las normas que se propone derogar.

En cuanto al art. 313-b CP, se propone su derogación, no sugiriéndose tipología en reemplazo. Se trata de una hipótesis parcialmente demodé y de nula aplicación, resultando además potencialmente cubierta por delitos patrimoniales (estafas), sin perjuicio de la responsabilidad por el delito de lesión individual, en su caso.

conjuntamente: a) El que instalare o regentare un matadero clandestino; b) El que a sabiendas enviare o llevare animales para su beneficio a un matadero clandestino; c) El que interviniere en cualquier forma en el beneficio clandestino, y d) El que interviniere en cualquier forma en el transporte $\mathrm{o}$ comercio $\mathrm{o}$ expendio de carne provenientes del beneficio clandestino, sabiendo su origen o no pudiendo menos de conocerlo. // Art. $4^{\circ}$. "Los animales en pie y los ya beneficiados y los útiles y enseres destinados a la matanza, como asimismo el producto de las ventas de carnes, que se encontraren en un matadero clandestino o en faenas de beneficio clandestino, caerán en comiso. // Si el beneficio clandestino se efectuare en un vehículo de transporte, este también caerá en comiso, a menos que el dueño acredite que no estaba en conocimiento del uso que se le daba. //El juez que conociere del proceso ordenará entregar de inmediato a la autoridad administrativa correspondiente los animales en pie y las carnes provenientes del beneficio clandestino, a fin de que disponga su expendio o eliminación, previo examen de ellas por la autoridad sanitaria respectiva. El producto de la venta, en su caso, será puesto a disposición del tribunal y el comiso recaerá sobre dicho producido". 


\section{Apéndice 1 \\ Decisiones relevantes comprendidas en la propuesta de articulado}

(a modo de síntesis e índice)

1. Alcance del objeto material de la figura de intrusismo-médico; y si acaso la mera ostentación será punible (se proponen alternativas para lo primero, sugiriendo rechazar lo segundo; cfr. art. A)

2. Grado de concreción y entidad del peligro asociado a las figuras de circulación de productos (se propone regulación, en general en línea con la idea de un peligro abstracto-concreto o delito de idoneidad; se deslizan con todo fórmulas que podrían sugerir una exigencia de peligro concreto; cfr. art. B y ss.)

3. Alcance de los objetos materiales cubiertos por los tipos de circulación de productos (situación de sangre, artículos para implante, alcoholes, tabacos, juguetes, elementos de seguridad y productos de consumo en general; se ponen en evidencia para una mejor discusión; cfr. art. B y ss., especialmente E)

4. Pertinencia y alcance de un tipo de omisión propia para casos de conocimiento subsecuente de la peligrosidad de los productos (se propone una regulación especial, como artículo C)

5. Pertinencia y alcance de un tipo especial de sabotaje: envenenamiento y otros; (se propone regulación, de modo que también resulta clara su diferencia con los tipos de responsabilidad por el producto; cfr. art. G)

6. Pertinencia y alcance de una regla especial de pena para casos de resultados de muerte o lesiones (como alternativa a un modelo de solución vía Parte General, en simple régimen concursal); (se propone regulación ad hoc, excluyente del concurso; cfr. art. H).

7. Pertinencia de una regla relativa a la prueba de la causalidad de resultados (no se propone regulación)

8. Pertinencia y alcance de una regla de desistimiento o arrepentimiento eficaz (se propone regulación especial; cfr. art. I)

9. Pertinencia y alcance de una regla de imputación (de autoría) en contextos de intervención en contextos organizados (se propone regulación especial; cfr. art. F)

10. Pertinencia y alcance de la punibilidad de la tentativa (no se propone regulación)

11. Alcance de la fórmula de imputación a título de imprudencia (se propone regulación; cfr. art. J)

12. Incorporación de figuras pertinentes, actualmente en leyes especiales (se proponen dos figuras; cfr. art. K y L) 
Londoño - Bases para una propuesta de reforma en materia de delitos contra la salud...

\section{Apéndice 2}

Comparado de la propuesta contenida en el informe versus el Proyecto de ley presentado al Congreso Nacional el 10 de marzo de 2014 (Mensaje Boletín No 9274-07).

\begin{tabular}{|c|c|}
\hline Propuesta de articulado del informe 82 & Proyecto de ley. Mensaje Boletín No 9274-07. \\
\hline $\begin{array}{l}\text { Título ... : "Delitos de peligro común" } \\
\text { Párrafo...: "Delitos relativos a la salud pública" }\end{array}$ & $\begin{array}{l}\text { Título XIV: "Delitos contra la seguridad } \\
\text { colectiva" } \\
\text { Párrafo } 4^{\circ} \text { : "Delitos contra la salud pública" }\end{array}$ \\
\hline $\begin{array}{l}\text { Apartado 1. Ejercicio no autorizado de la } \\
\text { medicina y profesiones del área salud }\end{array}$ & \\
\hline $\begin{array}{l}\text { Art. A. Con pena de }\left[{ }^{*}\right] \text { será sancionado el } \\
\text { que, sin contar con la competente } \\
\text { habilitación, [ostentare la calidad o] ejerciere } \\
\text { actividades propias de [profesiones } \\
\text { relacionadas con la conservación y } \\
\text { restablecimiento de la salud humana y que } \\
\text { requieran licenciatura universitaria] / [la } \\
\text { medicina alopática, enfermería, } \\
\text { fonoaudiología, kinesiología, obstetricia, } \\
\text { nutricionismo, tecnología médica, terapia } \\
\text { ocupacional, odontología, química y farmacia, } \\
\text { bioquímica \{y psicología\}]. }\end{array}$ & $\begin{array}{l}\text { Art. 538. Ejercicio ilegal de profesiones } \\
\text { médicas. El que sin contar con la competente } \\
\text { habilitación ejerciere actividades propias de } \\
\text { las profesiones relacionadas con la } \\
\text { conservación y restablecimiento de la salud } \\
\text { humana y que requirieren licenciatura } \\
\text { universitaria, será sancionado con prisión de } 1 \\
\text { a } 3 \text { años y multa. }\end{array}$ \\
\hline $\begin{array}{l}\text { Con [igual] pena será sancionado el que, } \\
\text { validando indebidamente una calidad, } \\
\text { decidiendo una contratación, prestando su } \\
\text { nombre o de cualquier otra forma relevante, } \\
\text { hiciere posible el ejercicio a que se refiere el } \\
\text { inciso anterior. } \\
\text { [No se entenderá que ejercen actividades } \\
\text { propias de las profesiones a que se refiere el } \\
\text { inciso primero, quienes desarrollen actividades } \\
\text { circunscritas a las profesiones auxiliares de la } \\
\text { salud o bien a la denominada medicina } \\
\text { alternativa complementaria fnaturopatía, } \\
\text { quiromasaje, acupuntura, terapia floral, } \\
\text { homeopatía u otras afines\}, en la medida que } \\
\text { se sujeten a las autorizaciones legales o } \\
\text { administrativas pertinentes. Tampoco se } \\
\text { entenderá que ejercen actividades propias de } \\
\text { las profesiones a que se refiere el inciso } \\
\text { primero, quienes practiquen la medicina } \\
\text { tradicional de comunidades indígenas, o lleven }\end{array}$ & \\
\hline
\end{tabular}

82 Simbología utilizada: en el propio cuerpo del articulado se incluyen formulaciones alternativas o se resaltan pasajes opcionales-complementarios. Para ello se optó por el uso de [corchetes] o del signo “/”, en su caso. En fin, en cuanto a las penas, se usan asteriscos $\left(^{*}\right)$, para destacar las diferencias de quantum esperables para cada figura (en escala relativa, interna a la presente rúbrica). 


\begin{tabular}{|c|c|}
\hline $\begin{array}{l}\text { a cabo otras prácticas afines de inveterada } \\
\text { raigambre en el territorio]. }\end{array}$ & \\
\hline $\begin{array}{l}\text { La propuesta no se hacía cargo de estas figuras } \\
\text { (véase supra Fundamentación General). }\end{array}$ & $\begin{array}{l}\text { Art. 539. Prácticas eugenésicas }[\ldots] \\
\text { Art. 540. Prácticas indebidas de asistencia a la } \\
\text { procreación }[\ldots] \\
\text { Art } 541 . \text { Extracción ilegal de árganos }[\ldots] \\
\text { Art. } 542 \text {. Tráfico de órganos }[\ldots]\end{array}$ \\
\hline $\begin{array}{l}\text { Apartado 2. Circulación de sustancias o } \\
\text { elementos, con creación de peligro común } \\
\text { (cfr. arts. } 313 \text { d, } 314 \text { y } 315 \text { CP vigente) }\end{array}$ & \\
\hline $\begin{array}{l}\text { Art. B. El que elaborare para expender, } \\
\text { expendiere o importare sustancias o } \\
\text { elementos destinados a la ingesta, consumo, } \\
\text { administración o aplicación a seres humanos } \\
\text { [con finalidades terapéuticas, alimenticias o } \\
\text { cosméticas], y que resultaren peligrosos para } \\
\text { la salud, ya por su carácter deteriorado, } \\
\text { infectado, adulterado o por apartarse de los } \\
\text { parámetros de calidad, proporción y } \\
\text { composición exigidos por la ley o los } \\
\text { reglamentos, será castigado con pena de [**]. } \\
\text { [Se entenderá que resultan peligrosos para la } \\
\text { salud humana aquellos objetos a que se refiere } \\
\text { el inciso anterior y que, bajo condiciones de } \\
\text { ingesta, administración o aplicación normales } \\
\text { para el tipo de finalidades a ellas asociadas, } \\
\text { incrementen el riesgo de provocar, agravar o } \\
\text { prolongar [, respecto de un número } \\
\text { indeterminado de personas,] afectaciones a la } \\
\text { salud superiores o equiparables a aquellas } \\
\text { consideradas [menos graves] en el marco de } \\
\text { los delitos contra la integridad física] }\end{array}$ & $\begin{array}{l}\text { Art. 543. Actividad con alimentos, } \\
\text { medicamentos y cosméticos peligrosos. El } \\
\text { que elaborare para expender, expendiere o } \\
\text { importare sustancias destinadas a la ingesta, } \\
\text { consumo, administración o aplicación a seres } \\
\text { humanos con finalidades terapéuticas, } \\
\text { alimenticias o cosméticas, que resultaren } \\
\text { peligrosas para la salud por su carácter } \\
\text { deteriorado, infectado o adulterado o por } \\
\text { apartarse de los parámetros de calidad, } \\
\text { proporción o composición exigidos por la ley } \\
\text { o los reglamentos será sancionado con prisión } \\
\text { de } 1 \text { a } 5 \text { años y multa. } \\
\text { Se entenderá que resultan peligrosas para la } \\
\text { salud las sustancias a que se refiere el inciso } \\
\text { anterior que, bajo condiciones normales de } \\
\text { ingesta, administración o aplicación sean } \\
\text { idóneas para provocar, agravar o prolongar } \\
\text { afectaciones a la salud. }\end{array}$ \\
\hline $\begin{array}{l}\text { Por su parte, con pena }\left[{ }^{*}\right] \text { será sancionado el } \\
\text { que elaborare, expendiere o importare las } \\
\text { sustancias o elementos a que se refiere el } \\
\text { inciso anterior, contraviniendo las } \\
\text { disposiciones legales o reglamentarias en } \\
\text { materia de información, rotulación o } \\
\text { advertencia necesarias para su segura ingesta, } \\
\text { administración o aplicación]. }\end{array}$ & $\begin{array}{l}\text { Art. 547. Información, rotulación y } \\
\text { advertencia. El que, contraviniendo las } \\
\text { disposiciones legales o reglamentarias en } \\
\text { materia de información, rotulación o } \\
\text { advertencia necesarias para su ingesta, } \\
\text { administración, aplicación o uso seguros, } \\
\text { expendiere las sustancias u objetos a que se } \\
\text { refieren los artículos 543, } 545 \text { y 546, será } \\
\text { sancionado con prisión de } 1 \text { a } 3 \text { años y multa } \\
\text { tratándose de las sustancias previstas en el } \\
\text { artículo 545, y con reclusión y multa en los } \\
\text { demás casos. }\end{array}$ \\
\hline $\begin{array}{l}\text { Art. C. Si el responsable de la elaboración, } \\
\text { expendio o importación de las sustancia o } \\
\text { elementos de que trata el artículo precedente }\end{array}$ & $\begin{array}{l}\text { Art. 548. Omisión. El responsable de la } \\
\text { elaboración, expendio o importación de las } \\
\text { sustancias u objetos de que tratan los artículos }\end{array}$ \\
\hline
\end{tabular}


viniese a conocer su peligrosidad en una fase posterior a su elaboración, expendio o importación, deberá sin demora [adoptar las medidas cautelares pertinentes] [dar noticia de ello a la autoridad y a los consumidores], en los casos y bajo las condiciones exigidos por la ley o los reglamentos. La omisión o defectuosa ejecución de dichas medidas será sancionada con la pena de $\left.{ }^{*}\right]$.
543,545 y 546 que, habiéndose impuesto de su peligrosidad solo con posterioridad a su elaboración, expendio o importación, omitiere adoptar las medidas cautelares pertinentes, dar noticia de ello a la autoridad y a los consumidores, en los casos y bajo las condiciones exigidos por la ley o los reglamentos, será sancionado:

$1^{\circ}$ con reclusión y multa o con prisión de 1 a 3 años y multa, tratándose de las sustancias a que se refiere el artículo 543;

$2^{\circ}$ con reclusión y multa en los demás casos.

Lo dispuesto en este artículo se entiende sin perjuicio de las penas que pudieren corresponder por los resultados lesivos que se ocasionaren.

Art. D. El que, sin contar con la competente autorización, elaborare, expendiere o importare sustancias o elementos terapéuticos [o cosméticos], será sancionado con pena [*], a menos que se configuraren los presupuestos del [inciso primero del] artículo B, caso en el cual la pena será de [***].

Con pena $\left.{ }^{*}\right]$ será sancionado quien, en el marco de un proceso de autorización para el desarrollo de las actividades a que alude el inciso precedente, hubiere aportado antecedentes falsos, por sí mismos relevantes o idóneos para la obtención de una decisión favorable de la autoridad.

Art. E. El que elaborare, envasare, expendiere, importare, almacenare o manipulare sustancias o elementos peligrosos para la salud humana, distintos de los mencionadas en los artículos precedentes, contraviniendo las disposiciones legales o reglamentarias establecidas en atención al tipo de riesgo de que se trate, será sancionado con la pena de [**] [, en la medida que con su conducta hubiere puesto en peligro la salud de un número indeterminado de personas]. competente autorización, elaborare para expender, expendiere o importare sustancias terapéuticas, será sancionado con prisión de 1 a 3 años y multa, a menos que se verificaren los presupuestos del inciso primero del artículo 526, caso en el cual se aplicará lo previsto para ese delito, considerándose que concurre en el hecho una agravante calificada.

Art. 545. Actividad con otras sustancias peligrosas. El que, contraviniendo las disposiciones legales o reglamentarias establecidas en atención al tipo de riesgo de que se trate, incluyendo las disposiciones relativas a envasado, elaborare para expender, expendiere o importare sustancias peligrosas para la salud humana, distintas de los mencionados en el artículo 543 será sancionado con prisión de 1 a 3 años y multa.

En las mismas penas incurrirá el que, contraviniendo las disposiciones legales o reglamentarias establecidas en atención al tipo de riesgo de que se trate, almacenare, transportare, tratare o abandonare tales sustancias, de un modo tal que pudieren
Art. 544. Actividad no autorizada con medicamentos. El que, sin contar con la 
Con [igual] pena será sancionado el que, contraviniendo las disposiciones legales o reglamentarias establecidas en atención al tipo de riesgos de que se trate, elaborare para expender, expendiere o importare, elementos destinados a resguardar de riesgos de muerte o grave enfermedad, intrínsecos o derivados de actividades productivas, extractivas o de servicios, en la medida que con su conducta hubiere puesto en peligro la salud de un número indeterminado de personas.

Lo dispuesto en el [artículo C] recibirá también aplicación en los supuestos a que se refiere este artículo.

Propuesta complementaria al inciso segundo propuesto: "Para los efectos de esta disposición, se reputarán igualmente peligrosos para la salud bumana aquellos elementos destinados a su uso corriente por infantes [, las bebidas alcohólicas, los tabacos] y todos aquellos elementos destinados a resguardar a seres bumanos de riesgos de muerte o grave enfermedad, intrínsecos o derivados de actividades productivas, extractivas o de servicios".

Art. F. Se reputará que realiza las conductas descritas en los artículos [precedentes de este apartado] y responderá por consiguiente con la penas previstas para el autor de los respectivos delitos, todo aquél que, en calidad de [socio principal, director, ejecutivo principal, liquidador, administrador o gerente] de una [entidad / personas jurídica] dedicada o relacionada al giro de que se trate, ejecute, ordene, autorice o tolere cualquier acto o práctica que contribuya a la configuración del [peligro / hecho punible]. En dicho supuesto, los demás agentes, internos o no a la [entidad / personas jurídica], que ejecuten o validen cualquier acto o práctica que contribuya a la configuración del [peligro / hecho punible], responderán con las penas previstas para los intervinientes. Con todo, de haber actuado estos sin el conocimiento de los mencionados superiores [socio principal, etc.], responderán con las penas previstas para los autores.

El funcionario público competente que validare las actuaciones de los particulares punibles en conformidad al inciso precedente, o no adoptare las medidas de su competencia para denunciar o impedir las conductas sancionadas en los artículos [B y E de este apartado], responderá con las penas previstas afectar la salud de quienes tomaren contacto con ellas.

Art. 546. Conductas relacionadas. Será sancionado con prisión de 1 a 3 años y multa, el que, contraviniendo las disposiciones legales o reglamentarias establecidas en atención al tipo de riesgo de que se trate, elaborare para expender, expendiere o importare:

$1^{\circ}$ objetos que contuvieren las sustancias previstas en el artículo precedente;

$2^{\circ}$ objetos destinados a proteger de riesgos de muerte o de grave enfermedad, intrínsecos o derivados de actividades productivas, extractivas o de servicios, de un modo tal que fueren peligrosos por no ser aptos para cumplir con dicha función;

$3^{\circ}$ objetos destinados al uso de niños, tales como juguetes o útiles escolares, que con facilidad pudieren ser manipulados de un modo que, atendida su composición, resultaren peligrosos para la salud

Reglas comunes de la Parte General (intervención en el delito: art. 35 ss. del Proyecto) 
para los [intervinientes] de dichos delitos. [De igual modo responderá el particular que hubiere otorgado certificaciones de idoneidad a las sustancias o elementos de que se trate].

Art. G. El que fuera de los casos previstos en los artículos [precedentes de este apartado], envenenare, infectare o adulterare aguas, sustancias o elementos destinados al consumo público, de modo que resulten peligrosos para la salud humana, será sancionado con pena [**]

Con [igual] pena será sancionado el que diseminare gérmenes patógenos idóneos para producir una enfermedad en la población.
Art. 549. Envenenamiento de sustancias u otras sustancias de consumo público. El que envenenare, infectare o adulterare aguas y otras sustancias destinadas al consumo público, de modo de hacerlas idóneas para provocar la muerte o una enfermedad grave a los potenciales consumidores, será sancionado con prisión de 3 a 9 años y multa.

Cuando las conductas previstas en el inciso precedente provocaren un peligro de menor entidad para la salud de los potenciales consumidores, se entenderá que realizan las exigencias del artículo 543.

Art. 550. Diseminación de gérmenes patógenos. El que diseminare gérmenes patógenos idóneos para producir enfermedad en la población será sancionado con prisión de 3 a 7 años y multa.

Art. H. Si de las conductas de que tratan las disposiciones [B, E y $G$ de este apartado], se derivaren afectaciones a la vida $\mathrm{O}$ integridad física de una o más personas, nacidas o que estuvieren por nacer, se aplicarán las siguientes penas:

1. La pena de $[* * * * * *]$, tratándose de resultados de muerte de una o más personas, en la medida que ellos fueren imputables a título de dolo, y la pena de [***], si los resultados fueren imputables a título de imprudencia.

2. Etc. (se propone incluir dos numerales más, con tramos de pena diferenciados para (1) resultados de malformaciones o lesiones $[$ de grave entidad]; y (2) resultados de lesiones [de mediana o leve entidad].

Tratándose de resultados derivados de la conducta a que se refiere el [artículo C], se aplicarán las penas mencionadas arriba, reducidas en $[\ldots]$
Art. 573. Muerte o lesiones graves. Si con ocasión de la comisión de los delitos previstos en los Párrafos 1,2 y 3 de este título y en los artículos 543, 544, 545, 546, 549, 550, 555, 556, 561, 562, 563, 566 y 568 el responsable matare a una persona o le irrogare alguna de las lesiones previstas en el inciso primero del artículo 223,, el tribunal estimará el hecho como una agravante muy calificada para fijar el mareo penal correspondiente a los delitos de homicidio o lesiones.

La pena a que se refiere y ordena fijar con mayor gravedad el inciso anterior se la comisión del delito el responsable causare la muerte o lesiones graves a una persona y ello fuere imputable a imprudencia temeraria. Si la muerte o las lesiones graves fueren imputables a simple imprudencia del responsable, el tribunal estimará el hecho como una agravante muy calificada de la pena que corresponda imponer conforme a las reglas generales.

En lo demás, para la aplicación de las penas antedichas junto con la pena establecida en los artículos de este título se estará a lo dispuesto en el artículo 82. impondrá también si con motivo u ocasión de 


\begin{tabular}{|c|c|}
\hline $\begin{array}{l}\text { Art. I. Quedará exento de pena por los delitos } \\
\text { de peligro de este apartado [o se beneficiará } \\
\text { con una rebaja en }[\ldots] \text { el responsable que } \\
\text { abandonare voluntariamente la prosecución } \\
\text { de su actuar o de cualquier modo eficaz } \\
\text { conjurare el peligro creado. La pena de } \\
\text { comiso procederá igualmente en estos casos. }\end{array}$ & $\begin{array}{l}\text { Reglas comunes de la Parte General } \\
\text { (desistimiento: art. } 33 \text { del Proyecto) }\end{array}$ \\
\hline $\begin{array}{l}\text { Art. J. El que por imprudencia diere lugar a [o } \\
\text { interviniere en] las conductas previstas en los } \\
\text { artículos }[\mathrm{B}, \mathrm{C}, \mathrm{E} \text { y } \mathrm{G}] \text { responderá [con las } \\
\text { penas que en cada caso se indican, rebajadas } \\
\text { en }\{\ldots\}] \text { / Alternativa: } \\
\text { 1. Con la pena de }[\ldots] \text { en el caso de } \\
\text { las conductas previstas en el artículo }[\ldots] \\
\text { 2. Con la pena de }[\ldots] \text { en el caso de } \\
\text { las conductas previstas en el artículo }[\ldots] \\
\text { 3. Con la pena de }[\ldots] \text { en el caso de } \\
\text { las conductas previstas en el artículo }[\ldots]\end{array}$ & $\begin{array}{l}\text { Art. } 551 \text { Imprudencia. El que } \\
\text { imprudentemente incurriere en las conductas } \\
\text { previstas en el inciso primero del artículo } 551 \\
{[\text { sic] } 83 \text { y en el artículo precedente, será }} \\
\text { sancionado con prisión de } 1 \text { a } 3 \text { años y multa. } \\
\text { La realización imprudente de las conductas } \\
\text { previstas en los artículos } 543,545 \text { y } 546 \\
\text { será sancionada con multa y además podrá } \\
\text { ser sancionada con reclusión o prisión de } 1 \\
\text { a } 3 \text { años. } \\
\text { La realización imprudente de la conducta del } \\
\text { artículo } 547 \text {, será sancionada con multa o con } \\
\text { reclusión y multa. }\end{array}$ \\
\hline Apartado 3. Otros delitos contra la salud pública & \\
\hline $\begin{array}{l}\text { Art. K. El profesional de la salud o } \\
\text { encargado de un centro de atención médica } \\
\text { que omitiere dar cuenta a la autoridad sobre } \\
\text { la existencia de un posible caso de } \\
\text { enfermedad o causa infecciosa, que viniere a } \\
\text { conocer en el desempeño de sus funciones y } \\
\text { respecto de la cual las leyes o reglamentos } \\
\text { exigieren notificación inmediata, será } \\
\text { sancionado con pena [*]. Dicha sanción solo } \\
\text { se impondrá en la medida que se demostrare } \\
\text { efectivo el brote de la enfermedad o causa } \\
\text { infecciosa en cuestión. } \\
\text { En los mismos términos será sancionada la } \\
\text { autoridad que, tomando conocimiento de la } \\
\text { notificación a que se refiere el inciso } \\
\text { precedente, no adoptare las providencias o } \\
\text { medidas requeridas por la leyes y reglamentos } \\
\text { para dicho evento. }\end{array}$ & $\begin{array}{l}\text { Art. 552. Enfermedad infecciosa. El } \\
\text { profesional de la salud o encargado de un } \\
\text { centro de atención médica que omitiere dar } \\
\text { cuenta a la autoridad competente sobre la } \\
\text { existencia de un posible caso de enfermedad } \\
\text { o causa infecciosa de que tomare } \\
\text { conocimiento en el desempeño de sus } \\
\text { funciones y respecto de la cual las leyes o } \\
\text { reglamentos exigieren notificación inmediata, } \\
\text { será sancionado con prisión de } 1 \text { a } 3 \text { años. } \\
\text { Dicha sanción solo se impondrá en la medida } \\
\text { que se demostrare efectivo el brote de la } \\
\text { enfermedad o causa infecciosa en cuestión. } \\
\text { En los mismos términos será sancionada la } \\
\text { autoridad competente que, tomando } \\
\text { conocimiento de la notificación a que se } \\
\text { refiere el inciso precedente, no adoptare las } \\
\text { providencias o medidas requeridas por la } \\
\text { leyes y reglamentos para dicho evento. }\end{array}$ \\
\hline $\begin{array}{l}\text { Si las conductas } \\
\text { anteriores solo } \mathrm{p}\end{array}$ & \\
\hline
\end{tabular}

${ }^{83} \mathrm{La}$ referencia es errónea y a nuestro juicio debe entenderse hecha al artículo 349 del Proyecto. 
Londoño - Bases para una propuesta de reforma en materia de delitos contra la salud...

\begin{tabular}{|c|c|}
\hline imprudencia, se aplicará la pena $[<*]$. & \\
\hline $\begin{array}{l}\text { Art. L. El responsable o administrador de un } \\
\text { matadero clandestino, el que ponga o envíe } \\
\text { animales para su beneficio allí, el responsable } \\
\text { o administrador del transporte de los } \\
\text { productos del matadero clandestino y el que } \\
\text { lo sea de su expendio, será sancionado con } \\
\text { pena }[\ldots] \text {. }\end{array}$ & $\begin{array}{l}\text { Art. 553. Matadero clandestino. El } \\
\text { responsable o administrador de un matadero } \\
\text { clandestino, el que ponga o envíe animales } \\
\text { para su beneficio en el mismo, el responsable } \\
\text { o administrador del transporte de los } \\
\text { productos del matadero clandestino y el que } \\
\text { lo sea de su expendio, será sancionado con } \\
\text { prisión de } 1 \text { a } 5 \text { años y multa. }\end{array}$ \\
\hline $\begin{array}{l}\text { La propuesta no se hacía cargo de estas figuras } \\
\text { (véase supra Fundamentación General). }\end{array}$ & $\begin{array}{l}\text { Art. 554. Inhumación y exhumación ilegal de } \\
\text { cadáver. El que sin estar debidamente } \\
\text { autorizado practicare la inhumación o } \\
\text { exhumación de un cadáver, o trasladare un } \\
\text { cadáver o partes de él, será sancionado con } \\
\text { multa o reclusión. } \\
\text { Cuando la exhumación se realizare con ánimo } \\
\text { de profanación o ultraje se estará a lo } \\
\text { dispuesto en el artículo } 473 \text {. }\end{array}$ \\
\hline $\begin{array}{l}\text { Art. M. Deróguense las siguientes } \\
\text { disposiciones: arts. } 42,43 \text { y } 44 \text { de la ley } 18.455 \\
\text { (alcoholes nocivos y otros); art. } 170 \text { de la ley } \\
\text { 16.464 (alimentos nocivos); arts. } 3 \text { y } 4 \text { de la } \\
\text { ley } 11.564 \text { (mataderos clandestinos), art. } 27 \\
\text { ley } 17.164 \text { (intrusismo-tecnólogos médicos), } \\
\text { art. } 25 \text { ley } 17.033 \text { (intrusismo-psicólogos); art. } \\
36 \mathrm{DFL} 1 \text { de } 1970 \text { (intrusismo-kinesiólogos). } \\
\text { Nota: se da por descontada la derogación de las } \\
\text { siguientes faltas del CP vigente: } N^{\circ} \text { s } 7 \text { y art. } 494 \\
\text { (despacho de medicamento sin receta y ejercicio ilegal } \\
\text { de medicina y otras afines) y } N^{\circ} \text { s } 19,20 \text { y } 22 \text { art. } \\
496 \text { (disposición no reglamentaria de animales } \\
\text { muertos, objetos insalubres y desperdicios). Otro tanto } \\
\text { cabe decir respecto al } 313 \text { b del CP, sobre el que se } \\
\text { dirá algo en la fundamentación particular. }\end{array}$ & $\begin{array}{l}\text { La Comisión elaboró una "Propuesta de Ley } \\
\text { de Introducción del Código Penal" que } \\
\text { incluía este tipo de derogaciones, entre otras } \\
\text { propuestas de adecuación normativa. }\end{array}$ \\
\hline
\end{tabular}




\section{BIBLIOGRAFÍA:}

* CONTRERAS, Lautaro (2015): "La responsabilidad penal del fabricante por la infracción de sus deberes de vigilancia, advertencia y retirada". Política Criminal (Vol. 10, No 19, Art. 9), pp. 266-296.

* COUSIÑo, Luis (1975), Derecho Penal Chileno. Parte General, t. I, $1^{\text {a }}$ ed. (Editorial Jurídica de Chile, Santiago).

* EtCheberry, Alfredo (1997), Derecho Penal. Parte Especial, t. IV, $3^{\text {a }}$ ed. (Editorial Jurídica de Chile, Santiago).

* HERNÁNDEZ, Héctor (2006), "El problema de la "causalidad general" en el derecho penal chileno (con ocasión del art. 232 del Anteproyecto de Nuevo Código Penal)", Política Criminal (Vol. 1, No1, A7), p. 1-33.

* MILOS HURTADO, Paulina (2012): “Las profesiones 'análogas' en el delito de ejercicio ilegal de la medicina del artículo 313 a) del código penal chileno: propuesta para su determinación", Revista de Derecho UCN (Coquimbo, v. 19, n. 1), pp. 197-239.

* MUÑOZ CONDE, Francisco (2002): Derecho Penal. Parte Especial, 14 a edición (Tirant Lo Blanch, Valencia).

* PACHECO, Joaquín (1870), El Código penal concordado y comentado, $4^{\mathrm{a}}$ ed. (Imprenta de Manuel Tello, Madrid).

* SAlAZAR, Andrés (2015): "El delito de mantención de la venta de alimentos defectuosos al público: Una revisión del artículo 315 del Código Penal a partir de la teoría de las presunciones y de la dogmática de los delitos de omisión propia”, Política Criminal (Vol. 10, № 19, Art. 11), pp. 318-361.

* VIGANÒ, Francesco, Responsabilidad penal por el producto defectuoso y técnicas de tutela de la salud colectiva (a propósito del caso de la "leche $A D N^{\prime \prime}$ ), working paper, julio de 2013, inédito. 